\title{
LA CUESTIÓN PREJUDICIAL EUROPEA ANTE PLANTEAMIENTOS MÁS QUE DUDOSOS
}

\author{
LUIS JIMENA QUESADA \\ Catedrático de Derecho constitucional \\ Universidad de Valencia
}

\begin{abstract}
SUMARIO
I. Consideraciones preliminares: la colaboración jurisdiccional cuando la duda no es razonable. II. Interrogantes constitucionales con respuesta preconcebida. III. Estrategias nacionales con expectativa controvertida. IV. Cuestionamientos internos con apuesta esperanzadora. V. Formulaciones domésticas con arriesgada pregunta innecesaria. VI. Algunos retos: doble prejudicialidad y prejudicialidad omisiva. VII. Reflexiones y propuestas finales: la evitación de una argucia procesal doméstica ante el TJUE.
\end{abstract}

\section{CONSIDERACIONES PRELIMINARES: LA COLABORACIÓN JURISDICCIONAL CUANDO LA DUDA NO ES RAZONABLE}

Como es sabido, la cuestión prejudicial ante el Tribunal de Justicia (TJUE) ${ }^{1}$ constituye el mecanismo de colaboración judicial por excelencia en el continente europeo, con un impacto incomparablemente mayor que la competencia consultiva (de dimensión más política) del $\mathrm{TEDH}^{2}$, o que la susceptible de ser proyectada por

1 Cabe recordar que el Tribunal de Justicia de la Unión Europea, como institución, está compuesto por dos configuraciones o jurisdicciones internas, es decir, el Tribunal de Justicia y el Tribunal General (en este último se han integrado desde 2016 los miembros del Tribunal de la Función Pública, que ha desaparecido). Por lo demás, el análisis se centrará en el Tribunal de Justicia como tal (en adelante, TJUE), sin entrar a valorar la menor incidencia de las cuestiones prejudiciales sustanciadas ante el Tribunal General (según lo previsto en el art. 256.3 TFUE).

2 Particularmente, la legitimación activa para activar esa competencia consultiva (art. 47 CEDH) queda circunscrita al Comité de Ministros del Consejo de Europa, monopolio que contrasta con el amplio espectro de sujetos legitimados al efecto ante la Corte Interamericana de Derechos Humanos, cuya función consultiva es más amplia y encaminada a «hacer más efectivos los derechos y libertades fundamentales»: SALVIOLI, F.: «La competencia consultiva de la Corte Interamericana de Derechos Humanos: marco legal y desarrollo jurisprudencial», en Os Rumbos do Direito Internacional dos Direitos Humanos. Ensaios em Homenagem ao 
la prejudicialidad prevista entre las jurisdicciones supremas nacionales y el Tribunal de Estrasburgo en el Protocolo n. ${ }^{\circ} 16$ al CEDH de 2 de octubre de $2013^{3}$. Tampoco tiene parangón el carácter más modesto de las consultas prejudiciales en la Comunidad Andina con la cuestión prejudicial del art. 267 TFUE $^{4}$.

Realmente, cuando dicho precepto establece la facultad del órgano jurisdiccional nacional («podrá pedir») para dirigirse al TJUE a propósito de la interpretación del Derecho primario o de la validez e interpretación del Derecho secundario «si estima necesaria una decisión al respecto para poder emitir su fallo» (facultad que deviene obligación cuando las decisiones de la instancia doméstica «no sean susceptibles de ulterior recurso judicial de Derecho interno»), está instaurando un mecanismo nada despreciable relacionado con el amplio espectro del reparto del poder judicial europeo 5 .

Desde tal óptica, la cuestión prejudicial persigue una colaboración tendente a asegurar la coherencia interpretativa y la aplicación uniforme del Derecho de la UE por parte de los órganos jurisdiccionales de los Estados miembros, con el objetivo último de garantizar la efectividad de la tutela judicial haciendo valer los principios de igualdad y de seguridad jurídica en el espacio judicial único. Por añadidura, semejante colaboración entre la Justicia nacional y la Justicia comunitaria europea constituye una nítida expresión de diálogo judicial mediante el cual se manifiesta asimismo el principio de responsabilidad en el cumplimiento fiel y leal de las obligaciones europeas ${ }^{6}$.

Professor Antônio Augusto Cançado Trindade (Coord. LEAO, R. Z. R.), Porto Alegre, Brasil, Sergio Antonio Fabris Editor, 2005, tomo III, pp. 471-472.

3 Dicho Protocolo entrará en vigor cuando reúna diez ratificaciones. Hasta diciembre de 2016 contaba con seis ratificaciones (Albania, Finlandia, Georgia, Lituania, San Marino y Eslovenia); España ni siquiera lo ha firmado hasta la fecha. Para ponderar el alcance de dicho Protocolo, así como del n. ${ }^{\circ} 15$, puede leerse López Guerra, L.: «Los Protocolos de reforma n. ${ }^{\circ} 15$ y n. ${ }^{\circ} 16$ al Convenio Europeo de Derechos Humanos», Civitas. Revista Española de Derecho Europeo, n. ${ }^{\circ} 49,2014$, pp. 11-29.

4 Cienfuegos Mateo, M.: «Cuestiones prejudiciales en la Unión Europea y consultas prejudiciales en la Comunidad Andina: similitudes, diferencias e influencias», Revista Electrónica de Estudios Internacionales, n. ${ }^{\circ} 25,2013$, p. 40 .

5 En ese amplio sentido, como ha apuntado SARmiento Ramírez-Escudero, D.: El Derecho de la Unión Europea, Madrid, Marcial Pons, 2016, p. 358: «Como en todo sistema político compuesto y basado en el reparto de competencias, el poder judicial de la Unión se estructura en dos niveles: por un lado, los tribunales de la Unión y, por otro, los tribunales de los Estados miembros. Se trata de un poder judicial híbrido en el que los órganos de cada nivel ejercen unas competencias tasadas y definidas en los Tratados constitutivo. Según el art. 19 TUE, los tribunales de la Unión son el Tribunal de Justicia y el Tribunal General, integrados en la Institución que corona el poder judicial de la Unión: el Tribunal de Justicia de la Unión Europea. (...) El mismo art. 19 TUE añade, a continuación, que los tribunales de los Estados miembros están llamados a asegurar "las vías de recurso necesarias para garantizar la tutela judicial efectiva en los ámbitos cubiertos por el Derecho de la Unión”.» Del mismo autor, más ampliamente, ya con anterioridad, Poder Judicial e integración europea: la construcción de un modelo jurisdiccional para la Unión, Madrid, Civitas, 2004.

6 Puede argüirse, con carácter más exhaustivo, que se trata de dotar de vigencia, no sólo a la seguridad jurídica y a la responsabilidad, sino igualmente a los demás principios del Estado de Derecho (y, por extensión de la Comunidad de Derecho que es la UE) contenidos en los apartados 1 y 3 del art. 9 de la Constitución española (CE), así como al mandato de «garantía del cumplimiento» del Derecho europeo establecido en el art. 93 CE y al propio principio de cooperación leal consignado en el art. 4.3 TUE «para asegurar el 
Naturalmente, si bien el punto positivo de ese diálogo judicial supranacional, y más ampliamente global, consiste en una optimización de las soluciones en beneficio de la comunidad, el contrapunto viene dado por un debilitamiento de la responsabilidad ${ }^{7}$. Ésta puede quedar entonces diluida en los distintos actores dialogantes, hasta el punto de que la eventual falta de vertebración y ausencia de jerarquía conduce a una especie de soberanía supraestatal difusa en la que se tratará de evitar que impere una «ley de la jungla» ${ }^{8}$ para que se imponga esa leal y sincera colaboración?.

Dicho lo cual, tampoco cabe obviar que la cuestión prejudicial comporta la mayor carga de trabajo del TJUE ${ }^{10}$, de tal suerte que podría decirse que dicha vía incidental o indirecta, tanto en el plano cuantitativo como cualitativo, viene a hacer las veces de un inexistente recurso de amparo directo ante el Tribunal de Luxemburgo. Por supuesto, no constituye el objeto ni la pretensión del presente trabajo efectuar una disquisición sobre las potenciales bondades que presentaría semejante recurso de amparo ante el TJUE. Acaso el controvertido grado de efectividad a la vista, sobre todo, del altísimo índice de inadmisibilidad afectante a esta modalidad de acción directa de tutela en las experiencias de referencia (piénsese en el duro filtro de admisibilidad, con rechazo superior al noventa por ciento, en los supuestos del recurso de amparo ante el TC o de la demanda individual ante el TEDH) relativice las posibles virtudes de su inclusión en el seno del ordenamiento comunitario europeo (a la sazón frustrada con motivo de la adopción de la Carta de los Derechos Fundamentales de la Unión Europea, CDFUE) ${ }^{11}$.

cumplimiento de las obligaciones derivadas de los Tratados o resultantes de los actos de las instituciones de la Unión».

7 Nieto, A.: «Globalización y Administración Pública», en AA.VV.: La globalización más allá de la empresa, Castellón, Universitat Jaume I, 2003, pp. 45-46.

8 Ibidem, pp. 46-47.

9 Son numerosas las contribuciones en los últimos años sobre el diálogo judicial: entre ellas, DE VERGOTTINI, G.: «El diálogo entre Tribunales», Teoría y Realidad Constitucional, n. ${ }^{\circ}$ 20, 2011, pp. 337-352; GARCÍA RocA, J.: «El diálogo entre el Tribunal Europeo de Derechos humanos y los Tribunales Constitucionales en la construcción de un orden público europeo», Teoría y Realidad Constitucional, n. ${ }^{\circ}$ 30, 2012, pp. 183-224; Salvador Martinez, M.: «El diálogo entre tribunales y la garantía de los derechos en Europa», en Nuevas tendencias en la interpretación de los derechos fundamentales (Coords. GIMENO SENDRA, J.V. y REgUEIRO GARCíA, M. T.), Madrid, Universitas, 2015, pp. 45-58. Acúdase asimismo al elenco de contribuciones incluidas en el volumen Diálogo Jurisprudencial en Derechos Humanos. Entre Tribunales Constitucionales y Cortes Internacionales (Coords. Ferrer Mac-Gregor, E. y Herrera García, A.), Valencia, Tirant lo Blanch, 2013; así como a Gordillo PÉRez, L.I. (Dir.): Constitutionalism of European Supranational Courts. Recent developments and challenges, Cizur Menor, Thomson/Reuters-Aranzadi, 2015.

10 Según el Informe anual 2015 — Actividad Judicial, Luxemburgo, Tribunal de Justicia de la Unión Europea, 2016 (p. 85), las decisiones prejudiciales representan el 65,58\% de la actividad judicial del TJUE, seguidas de las decisiones sobre recursos de casación (20,62\%), sobre recursos directos (11,36\%), sobre recursos de casación en procedimientos sobre medidas provisionales o demandas de intervención (1.14\%) o sobre procedimientos especiales (también $1.14 \%$ ) y sobre solicitudes de dictámenes $(0.16 \%)$.

11 Sobre este punto, se ha criticado que la cuestión de las garantías jurisdiccionales no fue diseñada precisamente a la medida de la ciudadanía en la CDFUE: RALlo LombarTe, A.: «Las garantías jurisdiccionales de los Derechos Fundamentales reconocidos en la Carta de los Derechos Fundamentales de la Unión Europea», en 
De todos modos, podría llegar incluso a relativizarse el alcance del novedoso y amplio catálogo de la CDFUE, que a lo peor habría comportado la formalización de un estándar menos incisivo que el forjado con anterioridad por la jurisprudencia pretoriana del propio Tribunal de Justicia en ausencia de una «parte dogmática». Como se analizará más adelante (con ilustraciones concretas en apartados IV y V, infra), esa paradoja impregnaría especialmente la tabla de derechos sociales de la CDFUE que, en esencia recogida bajo la rúbrica «Solidaridad», guarda conexión con uno de los terrenos más abonados por las peticiones de decisión prejudicial, a saber, la política social.

Ciertamente, la jurisprudencia social del TJUE derivada de las cuestiones prejudiciales es nutrida y ha permitido profundizar en algunos ámbitos básicos del modelo social europeo (sobre todo, en materia de organización del tiempo de trabajo, relaciones laborales y no discriminación) a escala comunitaria. Ahora bien, es menester preservar ese acervo jurisprudencial ante eventuales vacilaciones en la postura del TJUE con relación al alcance de los derechos sociales incluidos en la CDFUE, a su self-restraint en dicha materia y en la forma de enfocar las competencias comunitarias, o a su concurrencia con otros niveles de protección. En realidad, esa articulación de los diversos estándares de protección de derechos fundamentales conforma una de las claves del constitucionalismo multinivel europeo ${ }^{12}$, con una significativa incidencia en ese ámbito de los derechos socio-laborales ${ }^{13}$.

A este respecto, acostumbramos en la doctrina constitucionalista a centrarnos más en la manera de gestionar las decisiones alcanzadas (señaladamente cuando arrojan divergencias interpretativas o dificultades aplicativas), una vez ya producidas, que en analizar y paliar las causas que nos conducen a semejantes disfunciones. Por tal razón, es este segundo enfoque (pretendidamente menos clásico y más original) el que guiará la presente contribución, con objeto no tanto de poner luz reparadora a soluciones conflictivas ya consumadas (outputs), sino más bien de anticiparnos para aclarar las sombras que provocan esos conflictos (inputs).

En concreto, sobre constituir la cuestión prejudicial la principal fuente de asuntos sustanciados ante el TJUE, dicho mecanismo tiene un impacto nada imperceptible en el orden constitucional de los Estados Miembros en términos cuantitativos y cualitativos y, por ello mismo, conviene examinar qué tipo de estrategia procesal impulsa a los propios órganos jurisdiccionales que formulan las peticiones de decisión prejudicial. Dicho sin tapujos: se trata de criticar constructivamente, para atemperar, las estrategias de las jurisdicciones nacionales que, más que propiciar la fluida articulación de los ordenamientos nacionales y

Comentarios a la Constitución Europea (Dirs. Álvarez Conde, E., y Garrido Mayol, V.), libro II, Valencia, Tirant lo Blanch/Consejo Jurídico Consultivo de la Comunitat Valenciana, 2004, pp. 1629-1652.

12 Freixes Sanjuán, T.: «Els drets fonamentals en perspectiva multinivell. Reflexions entorn dels seus efectes», Revista catalana de dret públic, n. ${ }^{\circ}$ 50, 2015, p. 41.

13 Vid. Valdés Dal-Ré, F.: El constitucionalismo laboral europeo y la protección multinivel de los derechos laborales fundamentales: luces y sombras, Albacete, Bomarzo, 2016. 
del Derecho de la UE, resultan nocivas para la tutela judicial efectiva y la mejora de la calidad de vida de las personas, al no verse inspiradas necesariamente por la apariencia de una buena fe jurisdiccional ni por el efecto útil de las normas europeas.

Desde luego, debe presuponerse la buena fe en la estrategia de los órganos jurisdiccionales nacionales al formular las cuestiones prejudiciales, pero, ya sea por problemas de formación y de la propia complejidad del Derecho de la UE, ya sea por una excepcional y voluntaria utilización distorsionadora de tal mecanismo, apelar a esa colaboración judicial ante el TJUE cuando la duda no sea razonable, comporta un reprochable ejercicio de irresponsabilidad constitucional y de deslealtad comunitaria en detrimento del correcto engranaje institucional, así como de la optimización del sistema de fuentes y del sistema de derechos fundamentales. En estas condiciones, resulta lamentable abusar de la colaboración judicial cuando la duda no sea razonable; pero, correlativamente, constituye asimismo un planteamiento más que dudoso el hecho de no acudir a dicha colaboración cuando se cumplan las condiciones previstas en el art. 267 TFUE (sobre todo, cuando se trate de la última instancia jurisdiccional interna y, por ende, medie la obligación de activar la prejudicialidad).

Pues bien, en los apartados siguientes se intenta ofrecer un análisis crítico-constructivo de las claves de esos planteamientos reveladores de una controvertida «duda metódica», ya se trate de la búsqueda de una previsible solución europea más restrictiva (apartados II y III), ya se trate de la apuesta por una improbable solución europea más favorable (apartados IV y V). En coherencia con ello, se someten a escrutinio dos retos importantes estrechamente imbricados con esa duda metódica, o sea, el riesgo de hacer aflorar contenciosos paralelos con soluciones divergentes y la deliberada omisión de la obligada formulación de la cuestión prejudicial (apartado VI), completándose el estudio con unas reflexiones y propuestas finales que conjuren el peligro de una actitud displicente imbuida de espíritu reacio a la colaboración (apartado VII).

\section{INTERROGANTES CONSTITUCIONALES CON RESPUESTA PRECONCEBIDA}

Tenemos sobradamente asumido que los órganos jurisdiccionales ordinarios, ya desde la primera instancia, son los jueces comunitarios o europeos por antonomasia y, por tanto, se erigen en los naturales aplicadores del Derecho de la UE ${ }^{14}$, bien haciendo efectivos los principios de primacía y efecto directo o bien, en caso de duda fundada a tenor del art. 267 TFUE, planteando la correspondiente cuestión

14 Por todas, STC 213/1994, de 14 de julio, FJ 3. En la doctrina, léase el clásico libro de RuIZ-JaRABO Colomer, D.: El juez nacional como juez comunitario, Madrid, Civitas-Fundación Universidad Empresa, 1993. 
prejudicial. En la misma línea, pese a haberse sostenido repetidamente que el Derecho de la UE no forma parte del canon de constitucionalidad, o no es parámetro de constitucionalidad, por cuanto «la tarea de garantizar la recta aplicación del Derecho comunitario europeo por los poderes públicos nacionales es una cuestión de carácter infraconstitucional» ${ }^{15}$, dicha posición se revelaba insostenible ${ }^{16}$.

Así las cosas, como es conocido, las reticencias de la Jurisdicción Constitucional española al planteamiento de una cuestión prejudicial perduraron hasta 2011, año en que formuló la primera mediante el Auto 86/2011, de 9 de junio (asunto Melloni). Esa primera experiencia, empero, ha causado impresiones encontradas, en la medida en que: de un lado, cabe lamentar que nuestro TC no se incorporara antes a ese diálogo judicial (la Corte Constitucional italiana también tardó bastante, resistiéndose hasta el año 2002) ${ }^{17}$, como bien criticó Pablo Pérez Tremps en su voto particular a dicho Auto 86/2011 ${ }^{18}$; pero, de otro lado, el apriorístico aplauso a ese planteamiento en el plano procedimental no deja de suscitar una crítica en cuanto a la solución sustancial alcanzada, dado que el interrogante constitucional se orientaba hacia una respuesta preconcebida ${ }^{19}$ a la luz de la jurisprudencia previa del TJUE ${ }^{20}$.

15 Por todas, STC 233/2015, de 5 de noviembre, FJ 10, y la jurisprudencia constitucional allí citada.

16 De hecho, ya en la STC 147/1996, de 19 de septiembre, en uno de los votos particulares discrepantes (concretamente el suscrito por Diego González Campos) se criticaba que aunque la mayoría se apoyara «en una jurisprudencia consolidada del Tribunal sobre las relaciones entre el Derecho comunitario y la Constitución, en el presente caso la radical exclusión del primero supone, a mi entender, que la solución a la que se ha llegado en el fallo sea, en buena medida, tan inapropiada como irreal».

17 Passaglia, P. y otros: Corti costituzionali e rinvio pregiudiziale alla Corte di giustizia, Roma, Corte Costituzionale, abril 2010, http://www.cortecostituzionale.it/documenti/convegni_seminari/CC_SS_Corti_ costituzionali_rinvio_pregiudiziale_12012010.pdf (visitado el 9 de septiembre de 2016), p. 20: con las Ordenanzas (Autos) n. ${ }^{\circ} 102$ y 103 de 2002, la Corte Constitucional utilizó por primera vez el instrumento de la cuestión prejudicial prevista en el entonces art. 234 TCE (actual art. 267 TFUE), dando así el paso auspiciado desde hacía tiempo por la doctrina mayoritaria. Con tales decisiones «se sellaba el abandono, por parte del juez constitucional, de la posición rígida de clausura con respecto a la posibilidad de considerar como órgano legitimado para requerir directamente la intervención prejudicial del Tribunal de Luxemburgo, lo que hasta entonces había representado el obstáculo principal a la posibilidad de instaurar un diálogo directo con el supremo juez comunitario».

18 Se expresaba en estos términos Pablo Pérez Tremps: «Debo manifestar mi satisfacción y mi acuerdo con el hecho novedoso de que el Tribunal Constitucional español se sume a ese proceso jurídico que se ha denominado el 'diálogo de los tribunales' o ‘diálogo judicial europeo'. (...) plenamente de acuerdo con la decisión del Tribunal de abandonar estériles disputas de 'jerarquías jurisdiccionales' para integrarse en un mucho más fructífero diálogo entre las instancias jurisdiccionales nacionales, en concreto los tribunales constitucionales, y el Tribunal de Justicia de la Unión Europea, aunque en mi opinión este caso no cumpla técnicamente con las exigencias del art. 267 TFUE».

19 El Auto del TC tuvo su respuesta en la STJUE de 26 de febrero de 2013 (asunto C-399/11, Melloni), en cuya parte dispositiva (concretamente en el punto 3) declaraba: «El art. 53 CDFUE debe interpretarse en el sentido de que no permite que un Estado miembro subordine la entrega de una persona condenada en rebeldía a la condición de que la condena pueda ser revisada en el Estado miembro emisor, para evitar una vulneración del derecho a un proceso con todas las garantías y de los derechos de la defensa protegidos por su Constitución».

20 El antecedente esencial viene dado lógicamente por la STJUE de 3 de mayo de 2007 (Advocaten voor de Wereld VZW y Leden van de Ministerraad, asunto C-303/05), mediante la que se pronuncia directamente 
Luego, bajo tal ángulo sustancial, el planteamiento podía ser percibido como inútil ${ }^{21}$. Por el contrario, el TC confirma una posición comunitarista que indudablemente reconforta al TJUE haciendo prevalecer la dinámica de la integración a través de la armonización en la materia controvertida; lo cual, desde el punto de vista interno, apostaba por la eficacia integradora del art. 93 CE relegando el juego del art. 10.2 $\mathrm{CE}^{22}$. La solución del TJUE, en puridad, parecía paradójicamente reconfortar asimismo al Alto Tribunal español, que se veía abocado a acatar el fallo del TJUE mediante la STC 26/2014, de 13 de febrero, siquiera con la «boca pequeña $»^{23}$, tras aparentemente propugnar una interpretación al alza del art. 53 CDFUE en sus interrogantes ${ }^{24}$, señaladamente cuando el TC preguntaba: «ipermite el artículo 53, interpretado sistemáticamente en relación con los derechos reconocidos en los artículos 47 y 48 de la Carta, a un Estado miembro condicionar la entrega de una persona condenada en ausencia a que la condena pueda ser sometida a revisión en el Estado requirente, otorgando asi a esos derechos un mayor nivel de protección que el que se deriva del Derecho de la Unión Europea, a fin de evitar una interpretación limitativa o lesiva de un derecho fundamental reconocido por la Constitución de ese Estado miembro?».

En efecto, la interpretación armonizadora a la baja del art. 53 CDFUE efectuada en la STJUE Melloni de 26 de febrero de 2013 contó con el determinante apoyo previo de las Conclusiones del Abogado General Yves Bot, en las que propuso «rechazar con firmeza» la interpretación sugerida por el TC, en tanto en

sobre la Decisión marco 2002/584/JAI relativa a la euroorden, con motivo de una cuestión prejudicial planteada por el Arbitragehof belga en el marco de un recurso interpuesto por la asociación Advocaten voor de Wereld VZW ante el Arbitragehof con el fin de que se anulara la Ley belga de 19 de diciembre de 2003, relativa a la orden de detención europea. El fallo del Tribunal de Justicia apuesta por no poner reparos al proceso de integración europea, declarando textualmente que «el examen de las cuestiones planteadas no ha revelado ningún elemento que pueda afectar a la validez de la Decisión marco 2002/584/JAI del Consejo, de 13 de junio de 2002, relativa a la orden de detención europea y a los procedimientos de entrega entre Estados miembros»,

21 Arias Rodríguez, J.M.: «Sobre las cuestiones prejudiciales planteadas en el Auto del Tribunal Constitucional de 9 de junio de 2011 sobre la orden de detención europea», Diario La Ley, n. ${ }^{\circ}$ 7726, año XXIII, ref. D-407/2011, 31 de octubre de 2011.

22 Guillén López, E.: «Spain. The impact of the European Convention of Human Rights and the Charter of Fundamental Rights of the European Union on Spanish Constitutional Law: make a virtue of necessity", en Human Rights Protection in the European Legal Order: the interaction between the European and the National Courts (Coords. Popelier, P., Van de Heyning, C., y Van Nuffel, P.), Cambridge, Intersentia, 2011, p. 334.

23 Huelín Martínes de Velasco, J.: «La sentencia del Tribunal Constitucional 26/2014 (Melloni)», Revista de Jurisprudencia, ${ }^{\circ}{ }^{\circ} 1,1$ de julio de 2014, http://www.elderecho.com/tribuna/administrativo/sentencia_melloni_11_724930004.html (visitado el 7 de diciembre de 2016).

24 Esa interpretación al alza se ve inspirada por el principio favor libertatis, o, si se prefiere «el principio de presunción de la máxima expansión de las libertades constitucionales»: BARILE, P.: Diritti dell'uomo e libertà fondamentali, Torino, Il Mulino, 1984, pp. 34 y ss. Con respecto a dicho principio expresado por Barile, se ha traído a colación precisamente el art. 53 CDFUE por parte de SiLveSTRI, G.: «Verso uno ius commune europeo dei diritti fondamentali», en Ruolo della civilistica italiana nel processo di costruzione della nuova Europa (Dir. SCALISI, V.), Milano, Giuffrè, 2007, p. 67. 
cuanto ella «lesionaría el principio de primacía del Derecho de la Unión, ya que conduciría a atribuir la prioridad en cada caso específico a la norma jurídica que concediera el grado de protección más alto al derecho fundamental considerado. En algunos casos se reconocería así la preeminencia de las Constituciones nacionales sobre el Derecho de la Unión» ${ }^{25}$.

Sin embargo, el debate sigue abierto, puesto que en ese espacio de libertad, seguridad y justicia en el que ha irrumpido el «caso Melloni» ya mediaron sentencias constitucionales que pusieron en entredicho la euroorden, tanto a través de un juicio abstracto (Alemania) ${ }^{26}$ como de un reproche concreto (España) ${ }^{27}$, sentencias que fueron objeto de aplauso y de oposición en ambos países. Lo cierto es que la jurisprudencia Melloni ha seguido confirmándose por parte del TJUE ${ }^{28}$, lo cual no ha alejado el fantasma de la teoría de los «contra-límites» ${ }^{29}$ (cuestionando

25 Apartado 97. Léanse en la misma línea los apartados 98 y 99 de esas Conclusiones.

26 En particular, la Sentencia de 18 de julio de 2005 del Tribunal Constitucional Federal Alemán Bundesverfassungsgericht (BVergG, 2 BvR 2236/04, 18.7.2005). Puede accederse al texto en la dirección: http:// www.bverfg.de/entscheidungen/rs20050718_2bvr223604.html), que declaró la nulidad de la Ley alemana de 21 de julio de 2004 que incorporaba la euroorden por cuanto, en esencia, dicha ley no preveía la negativa a entregar a la persona reclamada cuando el delito se hubiera cometido en Alemania ni permitía interponer un recurso contra la decisión de entrega. Críticas a dicho pronunciamiento en Tomuschat, Ch.: «Inconsistencias: la Sentencia del Tribunal Constitucional alemán de 18 de julio de 2005 sobre la orden europea de detención y entrega», Teoría y Realidad Constitucional, n. ${ }^{\circ}$ 18, 2006, pp. 256 y 263; y en Vidal Prado, C.: «Nuevos (y viejos) recelos del Tribunal Constitucional Federal Alemán frente a la eficacia del Derecho comunitario», Revista Española de Derecho Constitucional, n. ${ }^{\circ} 77$, mayo-agosto 2006, p. 274 . En sentido contrario, conviene recordar que la Sentencia constitucional alemana estuvo precedida por la postura hecha pública por ciento veintitrés profesores penalistas germanos oponiéndose a la transposición de la euroorden al ordenamiento de la República federal, en la medida en que tal medida acarreaba para ellos problemas de inconstitucionalidad: para una aproximación a esas tesis contrarias puede leerse Gomez-Jara DíEz, C.: «Orden de detención europea y Constitución europea: reflexiones sobre su fundamento en el principio de reconocimiento mutuo», La Ley, n. ${ }^{\circ} 6069$, de 26 de julio de 2004, p. 3.

27 Entre otras, STC 177/2006, de 5 de junio. Crítico con dicho pronunciamiento se ha mostrado DE LA QuAdra-Salcedo Janini, T.: «El encaje constitucional del nuevo sistema europeo de detención y entrega (reflexiones tras la STC 177/2006, de 5 de junio)», Revista Española de Derecho Constitucional, n. . 78, 2006, p. 302. En el plano legislativo, véase el anterior balance crítico efectuado por ArANGÜENA FANEGo, C.: «La Orden Europea de Detención y Entrega. Análisis de las Leyes 2 y 3 de 14 de marzo de 2003, de transposición al ordenamiento jurídico español de la decisión marco sobre la euroorden», Revista de Derecho Penal, n. ${ }^{\circ}$ 10, 2003, pp. 94-95.

28 Entre otras, SSTJUE de 5 de abril de 2016, Pál Aranyosi y Robert Căldăraru (asuntos acumulados C-404/15 y C-659/15 PPU, apartado 76), o Pawel Dworzecki (asunto C-108/16 PPU, apartado 42).

29 Huelín Martínes de Velasco, J.: «La sentencia del Tribunal Constitucional 26/2014 (Melloni)», ya cit. Trayendo a colación el discurso de ingreso de Ricardo Alonso García en la Real Academia de Jurisprudencia y Legislación, leído el 24 de febrero de 2014, sintetiza Huelín que «el profesor Alonso García defiende que el parámetro 'efecto útil' debe ceder espacio a un discurso propio y sui generis de los derechos fundamentales: al abordar los posibles desplazamientos de los estándares de la Carta por superiores estándares nacionales; la lógica de los derechos fundamentales debe imponerse a un discurso cimentado en la pura efectividad. De no seguir tales derroteros, augura un renacimiento, desde los tribunales constitucionales de los Estados miembros, de la doctrina de los contra-límites al derecho de la Unión elaborada en Italia y en Alemania en la década de los setenta del siglo pasado». En la doctrina italiana, léase SAlmoni, F.: «La Corte Costituzionale, la Corte di Giustizia delle Comunità Europee e la tutela dei diritti fondamentali», en La Corte Costituzionale e le Corti d'Europa (Coord. Falzea, P., Spadaro, A., y Ventura, L.), Torino, Giappichelli, 2003, especialmente el epígrafe 6 ( «L'affermazione della teoria dei controlimiti e la risposta del Giudice del Lussemburgo: la tutela comunitaria dei diritti»), pp. 305-310. 
la superioridad del Derecho de la UE cuando se pongan en entredicho los principios y derechos que configuran la «identidad constitucional» o la «reserva constitucional» nacional ${ }^{30}$ ).

En este escenario, otras Jurisdicciones Constitucionales se han sumado a ese diálogo con el TJUE ${ }^{31}$ siendo, sin lugar a dudas, la iniciativa más saludada la llevada a cabo por el Bundesverfassungsgericht Alemán, que dio lugar a la importante

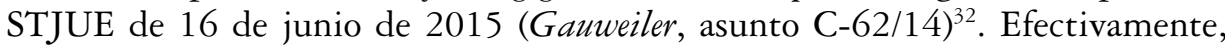
por más que los Tribunales Constitucionales se hayan mostrado finalmente abiertos en el plano procedimental a la formulación de cuestiones prejudiciales ${ }^{33}$, debe tenerse presente que la controversia no se plantea únicamente en términos de potencial conflicto entre Jurisdicción Comunitaria y Jurisdicción Constitucional ${ }^{34}$, al no poder quedar en absoluto excluido del diálogo el $\mathrm{TEDH}^{35}$.

30 Sobre la idea de «reserva de constitucionalidad» en el caso de Francia, puede leerse la Decisión del Consejo Constitucional DC n. ${ }^{\circ}$ 2006-540 DC de 25 de julio de 2006 (Ley relativa al derecho de autor y derechos afines en la sociedad de la información), así como el trabajo de ZiNAMSGVARov, N.: «L'identité constitutionnelle française: un circept», Civitas Europa, n. ${ }^{\circ}$ 21, 2008, pp. 365-384.

31 Entre otros pronunciamientos relevantes, pueden leerse la STJUE de 28 de julio de 2016 (Ordre des barreaux francophones et germanophones y otros, asunto C-543/14, cuestión prejudicial planteada por la Cour constitutionnelle de Bélgica, sobre sujeción a IVA de servicios prestados por abogacía); o la STJUE de 19 de julio de 2016 (Tadej Kotnik y otros, asunto C-526/14, cuestión prejudicial formulada por el Ustavno sodiřče, Tribunal Constitucional de Eslovenia, sobre ayudas de Estado a los bancos en el contexto de la crisis financiera). Resulta también de interés la STJUE de 16 de junio de 2016 (Franz Lesar, asunto C-159/15; la cuestión prejudicial fue planteada por el por el Verwaltungsgerichtshof, Tribunal Supremo de lo Contencioso-Administrativo de Austria, tras declararse incompetente previamente el Verfassungsgerichtshof, Tribunal Constitucional austríaco, sobre discriminación por motivos de edad en la determinación de los derechos a pensión de los funcionarios públicos).

32 Este pronunciamiento habría comportado un importante avance para el proceso de integración europea: Sarmiento Ramírez-Escudero, D.: «La Sentencia Gauweiler (C-62/14) del Tribunal de Justicia de la Unión Europea, sobre el programa de compra de deuda pública del Banco Central Europeo», Civitas. Revista Española de Derecho Europeo, n. ${ }^{\circ}$ 57, 2016, pp. 63 y ss.

33 En el caso alemán, valga la reflexión de Vidal Prado, C.: «Alemania», en Justicia Constitucional y Unión Europea (Coords. Tajadura Tejada, J. y De Miguel Bárcena, J.), Madrid, Centro de Estudios Políticos y Constitucionales, 2008, pp. 85-86: «Hay quien ha afirmado que alguno de los problemas causados por la Sentencia alemana sobre la Euroorden podría haberse evitado si el BVerfG hubiese acudido al TJUE, por medio de la presentación de una cuestión prejudicial, para aclarar aquellas cuestiones que el BVerfG no veía claras. (...) Comparto esta opinión: el instrumento de la cuestión prejudicial es uno de los más adecuados para articular la colaboración entre tribunales, pero ya conocemos los recelos del BVerfG y de otros Tribunales constitucionales (entre ellos el nuestro) a plantear estas cuestiones. (...) El celo por mantener la idea de que los Estados miembros continúan siendo 'señores de los tratados' (Herren der Verträge) y que, por tanto, a ellos corresponde la 'competencia de las competencias' (Kompetenz-Kompetenz) es, en algunos casos, exagerado, y puede distorsionar las relaciones de cooperación necesarias entre el TJUE y los tribunales constitucionales nacionales, en concreto, el BVerfG. La actitud negativa a plantear la cuestión prejudicial por parte del BVerfG y de otros Tribunales constitucionales es un claro reflejo de ello». Con anterioridad, un encuadre más exhaustivo de esta problemática, asimismo en VIDAL Prado, C.: El impacto del nuevo Derecho europeo en los Tribunales constitucionales, Madrid, Colex, 2004.

34 Macías Castaño, J.M.: La cuestión prejudicial europea y el Tribunal Constitucional. El asunto Melloni, Barcelona, Atelier, 2014, especialmente pp. 65-92 ( «Los Tribunales de los Estados Miembros de la UE con funciones constitucionales ante la cuestión prejudicial europea»).

35 Gordillo Pérez, L., y Tapia Trueba, A.: «Diálogos, monólogos y tertulias. Reflexiones a propósito del caso Melloni», Revista de Derecho Constitucional Europeo, n. ${ }^{\circ}$ 22, 2014, p. 269: «La tendencia hacia la 
Diversamente, en este polémico terreno, la «doctrina Bosphorus» de presunción del Derecho de la UE con relación al $\mathrm{CEDH}^{36}$ parece llamada a verse exceptuada por matizaciones y puntualizaciones en el marco de un diálogo judicial indefectible y justamente imbuido, tanto por un extenso espacio europeo común de derechos constitucionales ${ }^{37}$, como por el principio favor libertati ${ }^{38}$.

En fin, se me antoja que, a pesar de no abordar supuestos sustancialmente idénticos, una cierta matización de la «doctrina Melloni» en tal dirección se refleja en pronunciamientos recientes como la STC 77/2014, de 22 de mayo, en la que se trae explícitamente a colación la STJUE de 26 de febrero de 2013 (asunto C-399/11) a la luz de la jurisprudencia del TEDH en materia de juicio en ausencia del acusado, para acabar otorgando el amparo ${ }^{39}$.

\section{ESTRATEGIAS NACIONALES CON EXPECTATIVA CONTROVERTIDA}

Si en las reflexiones anteriores la crítica venía dada por la formulación de un interrogante aparentemente optimizador que en realidad atisbaba una respuesta más que previsiblemente restrictiva por parte del TJUE, en el presente apartado cabe cuestionar una estrategia procesal nacional ostensiblemente impregnada de espíritu reductor que por fortuna se saldó con un canon europeo más favorable.

Una ilustración paradigmática de ese proceder más que dudoso la suministra la STJUE de 22 de octubre de 2009 (Zurita García y Choque Cabrera, asuntos

equiparación de los estándares de protección servirá, sin duda de bálsamo, pero la multiplicación de los actores en estos procesos discursivos incrementará la litigiosidad y las posibilidades de sentencias discordantes. Quizá haya que mirar a Estrasburgo para encontrar al conductor final de esta tertulia»

36 STEDH (Gran Sala) Bosphorus Hava Yollari Turzim ve Ticaret Anonim Sirketi c. Irlanda de 30 de junio de 2005 .

37 La vigencia de la CDFUE, junto al principio de «no desviación» con respecto al CEDH y a la interpretación del TEDH, debería forjar en el seno de la UE un modelo de «derechos constitucionales» ampliable comparable al de la mayor parte de los Estados Miembros: Cruz Villalón, P.: «The 'added value' of the Charter 'in relation to' the European Convention on Human Rights», en Igualdad y democracia: el género como categoría de análisis jurídico. Estudios en Homenaje a la Profesora Julia Sevilla, Valencia, Corts Valencianes, 2014, p. 214.

38 López Guerra, L.: «El diálogo entre el Tribunal Europeo de Derechos Humanos y los tribunales nacionales. Coincidencias y divergencias», Teoría y Realidad Constitucional, n. ${ }^{\circ}$ 32, 2013, pp. 140-141: «(...) la aplicación por los tribunales nacionales de la doctrina del Tribunal de Estrasburgo puede legítimamente verse sujeta a diversas matizaciones. (...) Es posible que, en algunos casos, los tribunales nacionales apliquen sin reservas la interpretación del Convenio llevada a cabo por el TEDH; es también posible que aun reconociendo el efecto de cosa interpretada, planteen la necesidad de una matización, o incluso una reconsideración de la doctrina del Tribunal, y así lo expongan en sus resoluciones. Cabe finalmente que las garantías de los derechos fundamentales contenidas en el ordenamiento interno sean superiores a las establecidas por el Convenio, según la jurisprudencia del Tribunal».

39 En su fallo, el TC declara vulnerado el derecho fundamental del demandante a la tutela judicial efectiva del art. 24.1 CE y le restablece en su derecho declarando la nulidad de las decisiones judiciales previas que habían avalado la continuación de la celebración de la vista oral en ausencia del recurrente, ordenando la retroacción de las actuaciones al momento anterior a la producción de dicho vicio procesal. 
acumulados C-261/08 y C-348/08), en donde se determina que la normativa Schengen no impone necesariamente la expulsión (puede ser sanción menor, como la multa, en aras del respeto del principio de proporcionalidad) para inmigrantes en situación irregular ${ }^{40}$.

La verdad es que la estrategia procesal del órgano jurisdiccional nacional (la Sala de lo Contencioso-Administrativo del TSJ de Murcia) vislumbraba una apuesta desafiante en el ámbito interno y fue objeto de claro contrapunto en sede jurisdiccional comunitaria. Concretamente, la pregunta formulada (apartado 29 de la STJUE Zurita) ${ }^{41}$ apuntaba claramente a puentear al Tribunal Supremo español (y el TJUE era consciente de ello) ${ }^{42}$, cuya doctrina casacional se había decantado por el respeto del principio de proporcionalidad (apartados 22 y 23), confirmando así los criterios más favorables previamente seguidos por buena parte de los Tribunales Superiores de Justicia en supuestos análogos ${ }^{43}$.

Por otro lado, llama la atención que, ante el Tribunal de Luxemburgo, incluso el propio Gobierno español curiosa y paradójicamente (dado que el litigio principal traía causa de las órdenes de expulsión, acompañadas de la prohibición de entrada en el espacio Schengen durante cinco años, dictadas por el propio Gobierno a través de sus delegaciones en la Región de Murcia) se opuso a la estrategia procesal pretendida por el tribunal nacional de remisión (propugnando la inadmisión - apartados 31 a 33-).

Se trata de un plausible cambio de actitud gubernamental que, a mayor abundamiento, concluyó con la solución favor libertatis del TJUE, precedida por el aval tanto de la Abogada General Juliane Kokott como de la misma Comisión Europea. A mi entender, esa solución favorable merece ser incontestablemente aplaudida, por cuanto en el plano sustancial efectúa una adecuada ponderación atribuyendo un razonable peso tanto al margen de apreciación nacional en un ámbito sólo parcialmente armonizado (que deriva de la dinámica de la «Europa a varias velocidades» surgida del espacio de Schengen) como al principio de proporcionalidad; y, adicionalmente, se confiere por el TJUE una interesante

40 El TJUE falló que el acervo de Schengen litigioso debe interpretarse «en el sentido de que, cuando un nacional de un tercer país se encuentra en situación irregular en el territorio de un Estado miembro porque no cumple o ha dejado de cumplir los requisitos relativos a la duración de la estancia aplicables en él, dicho Estado miembro no está obligado a adoptar contra él una resolución de expulsión».

41 Esta fue la concreta cuestión prejudicial: «¿Deben interpretarse las anteriores normas [del acervo de Schengen] en el sentido de que se oponen a una regulación, como la nacional y la jurisprudencia que la interpreta, que posibilita la sustitución de la expulsión, de todo aquel 'nacional de un tercer país' que no disponga de título habilitante para la entrada y permanencia en el territorio de la Unión Europea, por la imposición de una multa?».

42 Ya en el apartado 22 de la STJUE Zurita se lee que «de las resoluciones de remisión se deduce que el Tribunal Supremo ha interpretado la normativa nacional anteriormente citada en el sentido de que, al ser la expulsión una sanción, la decisión por la que se dicta debe estar motivada de modo específico y respetar el principio de proporcionalidad».

43 Entre otras muchas, pueden leerse las Sentencias del Tribunal Supremo (Sala de lo Contencioso-Administrativo, Sección 5..$^{a}$ ) de 24 de junio de 2008 (recurso de casación n. ${ }^{\circ}$ 1320/2005) o de 28 de noviembre de 2008 (recurso de casación n..$^{\circ}$ 9581/2003). 
efectividad al principio favor libertatis al descartar la versión lingüística (la española, frente a todas las demás versiones oficiales) más restrictiva de la normativa Schengen controvertida (apartados 52 a 56).

Por lo demás, resulta reconfortante comprobar en términos de potencial convergencia del canon constitucional y del canon europeo que, incluso unos meses antes de la STJUE Zurita, la Jurisdicción Constitucional ya había atemperado el rigor interpretativo del juego de las sanciones de expulsión y multa a través del deber de motivación como correlato del derecho fundamental a la tutela judicial efectiva. Así, mediante la STC 140/2009, de 15 de junio, se otorgaba el amparo al recurrente tras argumentarse que «la posibilidad legal de que se imponga ante su comisión la sanción de expulsión como sustitutiva de la de multa no constituye por sí misma justificación suficiente de la decisión ni, por tanto, exime a la Administración del deber, impuesto por el art. 24.1 CE, de hacer expresas las razones por las que, valorando los criterios establecidos legalmente para la graduación de las sanciones, se opta en el caso concreto por la sustitución de la sanción de multa por la de expulsión. Pues bien, la resolución sancionadora impugnada, que se limita a constatar la mera existencia de la conducta infractora, no contiene fundamentación alguna a partir de la cual puedan conocerse las razones de la Administración sancionadora por la que resulta procedente la expulsión» (FJ 5); lo que en el fallo comportaba la declaración de violación del art. 24 CE y la anulación de la resolución judicial litigiosa ${ }^{44}$.

Es interesante, además, que la STC 140/2009 reproche que «la ausencia de motivación resulta especialmente evidente en el presente caso, toda vez que el recurrente alegó insistentemente el hecho de tener una pareja estable y cuatro hijos menores de edad escolarizados en Pamplona en favor de la aplicación del principio de proporcionalidad para que no se sustituyera la pena de multa por la de expulsión, recibiendo como única respuesta que las circunstancias personales son absolutamente irrelevantes en este tipo de expedientes» (FJ 6). Si acaso, no puedo dejar de señalar que, a continuación, en ese mismo FJ 6, si bien se toma en consideración esa situación de arraigo familiar, tal circunstancia sigue poniéndose en relación con el art. $39 \mathrm{CE}$ (no susceptible formalmente de amparo constitucional) en lugar de con el art. $18 \mathrm{CE}$, rechazándose con empecinamiento la equiparación de este último con el art. $8 \mathrm{CEDH}$ y por más que el TC conozca la jurisprudencia específica del TEDH ${ }^{45}$. La doctrina constitucionalista española, en general, tampoco ha sido crítica con esa posición del $\mathrm{TC}^{46}$, a mi modo de ver absolutamente insostenible.

44 Concretamente, de la Sentencia de la Sala de lo Contencioso-Administrativo del TSJ de Navarra de 1 de abril de 2005 (rollo de apelación n. ${ }^{\circ}$ 38/2005).

45 En ese FJ 6 de la STC 140/2009 se citan, «por todas, SSTEDH de 2 de agosto de 2001, caso Boultif c. Suiza, o de 17 de abril de 2003, caso Yilmaz c. Alemania».

46 Véase Santolaya Machetti, P.: «El derecho a la vida privada y familiar (un contenido notablemente ampliado del derecho a la intimidad», en La Europa de los derechos. El Convenio Europeo de Derechos 
Expresado lo cual, debe hacerse notar finalmente que la «doctrina Zurita» se ha visto matizada a la baja por la jurisprudencia más reciente del TJUE, a consecuencia de las modificaciones en sentido restrictivo de la normativa europea (por ejemplo, la conocida como «Directiva de retorno» de 2008) y los planteamientos prejudiciales efectuados por los órganos jurisdiccionales nacionales. Lo ilustra la STJUE de 23 de abril de 2015 (Samir Zaizoune, asunto 38/14), que tiene su origen en la cuestión prejudicial formulada por la Sala de lo Contencioso-Administrativo del TSJ del País Vasco ${ }^{47}$. Como contrapunto, por último, debe mencionarse como relevante la previa STJUE de 17 de julio de 2014 (Thi Ly Pabm, asunto C-474/13), que vino a consagrar el principio de irrenunciabilidad de derechos fundamentales como trasunto del principio favor libertatis en un supuesto de extranjería, en donde se declara que la Directiva de retorno debe interpretarse en el sentido de que «no permite a un Estado miembro internar a efectos de expulsión a un nacional de un tercer país en un centro penitenciario con presos ordinarios ni siquiera en el caso de que dicho nacional haya accedido a ese internamiento».

\section{CUESTIONAMIENTOS INTERNOS CON APUESTA ESPERANZADORA}

En el bloque que acometo ahora tienen cabida estrategias de órganos jurisdiccionales nacionales que resultan dudosas en el plano procedimental, ya sea por el limitado alcance de la normativa procesal pertinente, ya sea por el momento procesal elegido (susceptible de generar divergencias entre el canon constitucional y el canon europeo), no obstante lo cual manifiestan un modus operandi guiado por la buena fe al propugnar una apuesta esperanzadora para el mejor disfrute de los derechos fundamentales.

Del primer supuesto estratégico merece la pena tomar como referente el «caso Sánchez Morcillo». En particular, la STJUE Sánchez Morcillo de 17 de julio de

\footnotetext{
Humanos (Coords. Santolaya, P., y García Roca, J.), Madrid, CEPC, 2. a ed., 2009, p. 552: al aludir a los «aspectos no íntimos que el TEDH ha deducido del derecho a la vida familiar», añade el citado autor que «constituyen un interesante elemento de contraste con nuestra jurisprudencia que, en líneas generales no ha seguido esta línea, sino que, cuando se ha enfrentado a uno de estos problemas ha tendido a analizarlo desde el punto de vista de la tutela judicial efectiva».

47 En su fallo, el TJUE declaró que «la Directiva 2008/115/CE del Parlamento Europeo y del Consejo, de 16 de diciembre de 2008, relativa a normas y procedimientos comunes en los Estados miembros para el retorno de los nacionales de terceros países en situación irregular, (...) debe interpretarse en el sentido de que se opone a la normativa de un Estado miembro, como la controvertida en el procedimiento principal, que, en caso de situación irregular de nacionales de terceros países en el territorio de dicho Estado, impone, dependiendo de las circunstancias, o bien una sanción de multa, o bien la expulsión, siendo ambas medidas excluyentes entre sí». Véase también la STJUE de 7 de junio de 2016 (Sélina Affum, asunto C-47/15), derivada de la cuestión prejudicial planteada por la Corte de Casación de Francia en relación asimismo con la interpretación y aplicación de la Directiva de retorno a propósito de la entrada irregular de la recurrente que da nombre al caso en el territorio francés y la prórroga de su internamiento.
} 
2014 (asunto C-169/14) tiene su origen en la cuestión prejudicial planteada por la Audiencia Provincial de Castellón con objeto de obtener una interpretación del artículo 7 de la Directiva 93/13/CEE del Consejo, de 5 de abril de 1993, sobre las cláusulas abusivas en los contratos celebrados con consumidores, en conjunción con el derecho a la tutela judicial efectiva reconocido en el art. 47 CDFUE. Dicha petición se presentó en el marco de un litigio entre los deudores (el Sr. Sánchez Morcillo y la Sra. Abril García) y la entidad bancaria acreedora, en relación con la oposición de los primeros a la ejecución hipotecaria relacionada con su vivienda.

Los hechos litigiosos derivan del incumplimiento por los recurrentes en el litigio principal de su obligación de pagar las cuotas mensuales para la devolución del préstamo, tras lo cual el banco presentó una demanda contra ellos solicitando el pago de la totalidad del préstamo junto con los intereses ordinarios y de demora, así como la venta en pública subasta de la finca hipotecada. Una vez iniciado el procedimiento de ejecución hipotecaria, los recurrentes en el litigio principal formularon oposición contra ésta, oposición que fue desestimada por el Juzgado de Primera Instancia n. ${ }^{\circ} 3$ de Castellón. Los recurrentes en el litigio principal interpusieron entonces recurso de apelación ante la Audiencia Provincial de Castellón, la cual suspendió el procedimiento tras considerar que, si bien el procedimiento civil español permite interponer recurso de apelación contra la resolución judicial que, tras estimar la oposición formulada por el deudor, ponga fin al procedimiento de ejecución hipotecaria, tal legislación procesal (art. 695.4 de la Ley de Enjuiciamiento Civil, LEC) no permite, en cambio, que el deudor cuya oposición haya sido desestimada interponga recurso de apelación contra la resolución judicial de primera instancia que ordene la continuación del procedimiento de ejecución.

Pues bien, las dudas que albergaba el órgano jurisdiccional remitente en cuanto a la compatibilidad de la mencionada normativa nacional con el objetivo de protección de los consumidores que persigue la Directiva 93/13, así como con el art. 47 CDFUE, fueron confirmadas por la STJUE Sánchez Morcillo de 17 de julio de 2014, que además vino precedida por el Auto del Presidente del Tribunal de Luxemburgo de someter el asunto al procedimiento acelerado previsto en el artículo 23bis) del Estatuto del TJUE y en el artículo 105.1 de su Reglamento de Procedimiento.

Ahora bien, la respuesta obtenida mediante la STJUE de 17 de julio de 2014 fue considerada insuficiente por la Audiencia Provincial de Castellón, dado que si bien se modificó rápidamente el art. 695.4 LEC mediante el Real Decreto-ley $11 / 2014^{48}$ para adaptarlo a dicho pronunciamiento (lo mismo que con anterioridad se había modificado el art. 695.1 LEC mediante la Ley $1 / 2013^{49}$ para adecuarlo a la

48 Real Decreto-ley 11/2014 de 5 de septiembre, de medidas urgentes en materia concursal.

49 Ley 1/2013, de 14 de mayo, de medidas para reforzar la protección a los deudores hipotecarios, reestructuración de deuda y alquiler social. 
STJUE de 14 de marzo de 2013, Aziz, C-415/11, ofreciendo la posibilidad al ejecutado de formular oposición al procedimiento de ejecución hipotecaria basándose en el carácter abusivo de una cláusula contractual que constituya el fundamento de la ejecución $)^{50}$, permanecía una insuficiencia normativa. Dicha laguna consistiría en que esas modificaciones reconocían al consumidor el derecho a recurrir en apelación una resolución por la que se desestima la oposición basada en el carácter abusivo de una cláusula contenida en el contrato del que resulta la deuda reclamada y que constituye el fundamento del título ejecutivo, no permitiendo en cambio apelar contra las resoluciones que desestiman la oposición cuando ésta se basa en las otras causas enumeradas en el apartado 1 del art. 695 de la LEC modificada.

Con estos parámetros, la Audiencia Provincial formuló una nueva cuestión prejudicial ante el TJUE ${ }^{51}$. Evidentemente, lo más adecuado habría sido pedir aclaración de la Sentencia de 17 de julio de 2014 para determinar si de ella podría desprenderse esa extensión de las causas de oposición en favor del deudor hipotecario (a diferencia del profesional, quien en claro agravio comparativo sí goza de dicha facultad como acreedor ejecutante), pero semejante aclaración o interpretación no está prevista en la normativa procedimental del TJUE a tenor del art. 43 de su Estatuto en conjunción con los arts. 104 y 158 de su Reglamento ${ }^{52}$.

50 Recientemente se ha puesto de manifiesto que la STJUE Aziz de 14 de marzo de 2013 ha dejado flecos pendientes, como la posible abusividad de la cláusula de sumisión a la venta extrajudicial, pese a que el Tribunal Supremo (Pleno de la Sala de lo Civil) haya considerado (en Sentencia n. ${ }^{\circ} 483$ de 14 de julio de 2016, recurso de casación n. ${ }^{\circ}$ 1668/2014) que no es abusiva dicha cláusula (que habilita al acreedor hipotecario para acudir a esa vía de la ejecución extrajudicial del art. 129 de la Ley Hipotecaria en caso de vencimiento anticipado): así, PÉrez HerezA, J.: «El Tribunal Supremo se pronuncia sobre el procedimiento de ejecución extrajudicial hipotecaria», El Notario del Siglo XXI, n. ${ }^{\circ}$ 69, 2016, pp. 42-46.

51 La formulación de ulteriores cuestiones prejudiciales es susceptible de dinamizarse cuando la solución europea no deja de generar incógnitas en el plano interno, como ha ocurrido recientemente con la mediática STJUE de 14 de septiembre de 2016 (Ana de Diego Porras, asunto C-596/14) en torno a la equiparación de contratos de trabajo fijos e interinos a efectos de indemnización tras la extinción de la relación laboral, que ha reavivado un debate en torno al llamado «contrato único» y ha llevado al Ministerio de Trabajo a crear incluso una comité de expertos para estudiar el modo de ejecutar dicho pronunciamiento. Sobre la panoplia de situaciones en las que un órgano jurisdiccional se ve llamado a plantear una nueva cuestión prejudicial, es interesante la tipología ofrecida por Riechenerg, K.: «¿Preguntar de nuevo al Tribunal de Justicia?», en VV.AA.: Derecho Comunitario: La Cuestión Prejudicial, Madrid/Vitoria-Gasteiz, Consejo General del Poder Judicial/Gobierno Vasco, 1994. Dicho autor nos acerca a diversos escenarios, pudiendo destacar los cuatro siguientes: a) la cuestión prejudicial plantea un interrogante jurídico que ya cuenta con un solución por sentencia previa del TJUE, en cuyo caso la primera cuestión se toma como «modelo» y, si las partes consultadas proponen el mantenimiento de la cuestión, se responde de modo sucinto (a tenor del art. 99 del Reglamento del TJUE, se responde mediante Auto); b) la cuestión prejudicial suscita un problema de interpretación de una sentencia del TJUE, pudiendo ser la jurisdicción nacional remitente la misma que dio origen a dicha sentencia (como sucede en el mencionado caso Sánchez Morcillo) o un órgano jurisdiccional diverso; c) la petición prejudicial postula una nueva valoración de una previa sentencia (véase apartado 10 de la Sentencia HAG, de 17 de octubre de 1990, asunto C-10/89); y d) la cuestión prejudicial insta al TJUE a rectificar o modificar su jurisprudencia anterior (por ejemplo, Sentencia Faccini Dori, de 14 de julio d 1994, asunto C-91/92, en la que se propone evolucionar hacia la eficacia directa horizontal —invocabilidad en litigios entre particulares- de las Directivas no transpuestas).

52 A tenor del art. 104 del Reglamento (interpretación de las decisiones prejudiciales): «1. El artículo 158 del presente Reglamento, relativo a la interpretación de las sentencias y autos, no será aplicable a las 
El TJUE se mostró circunspecto ante esa nueva petición de decisión prejudicial, ofreciendo una respuesta negativa mediante el Auto de 16 de julio de 2015 (asunto C-539/14, sobre esa posible aplicación de la Sentencia Sánchez Morcillo a causas de oposición no basadas en la Directiva de 1993$)^{53}$. En verdad, el interrogante de la Audiencia Provincial contenía una apuesta comprometida y esperanzadora a favor de la protección del derecho a la vivienda ${ }^{54}$. Pero el TJUE reacciona, como en los demás apuntes jurisprudenciales previos (SSTJUE Aziz de 14 de marzo de 2013, asunto C-415/11 y Sánchez Morcillo de 17 de julio de 2014, asunto C-169/14) y posteriores (Auto del TJUE de 23 de febrero de 2016, Garzón Ramos, asunto C-380/15) ${ }^{55}$, proporcionando en el Auto de 16 de julio de 2015 (asunto C-539/14) una solución anclada en la Directiva de 1993 sobre cláusulas abusivas en los contratos celebrados con consumidores desde una perspectiva prevalentemente procesal.

No se extraen, en contraste, consecuencias sustanciales del derecho a la vivienda previsto en el art. $34 \mathrm{CDFUE}^{56}$. Tal vez sea comprensible, hasta cierto punto, la postura del TJUE, a quien no debe maltratarse trasladándole la responsabilidad por una omisión legislativa (en materia de vivienda) que recae primordialmente en los

resoluciones adoptadas en respuesta a una petición de decisión prejudicial. 2. Corresponderá a los órganos jurisdiccionales nacionales apreciar si la decisión prejudicial les ofrece información suficiente o si les parece necesario someter al Tribunal una nueva petición de decisión prejudicial».

53 En el apartado 21 del Auto se justifica por el TJUE que responde a la cuestión prejudicial mediante este tipo de resolución, en lugar de sentencia: «En virtud del artículo 99 de su Reglamento de Procedimiento, cuando una cuestión prejudicial sea idéntica a otra sobre la que el Tribunal ya haya resuelto, cuando la respuesta a tal cuestión pueda deducirse claramente de la jurisprudencia o cuando la respuesta a la cuestión prejudicial no suscite ninguna duda razonable, el Tribunal podrá decidir en cualquier momento, a propuesta del Juez Ponente y tras oír al Abogado General, resolver mediante auto motivado».

54 En el apartado 8 del Auto se sintetiza el contenido y objeto de la cuestión prejudicial: «el órgano jurisdiccional remitente sigue albergando dudas acerca de la compatibilidad de una disposición nacional de esa índole — en virtud de la cual debería desestimar el recurso de apelación interpuesto por los recurrentes en el litigio principal_ con el objetivo de protección de los consumidores perseguido por la Directiva 93/13, en relación con el principio de igualdad de armas consagrado por el artículo 47 de la Carta y los derechos a la vivienda y a la vida privada y familiar garantizados, respectivamente, por los artículos 34, apartado 3, y 7 de la Carta».

55 En dicho Auto se resolvió la cuestión prejudicial formulada por la Audiencia Provincial de les Illes Balears con objeto de dilucidar si era trasladable la doctrina de la STJUE Sánchez Morcillo de 17 de julio de 2014 y, tal caso, determinar si es compatible con el principio de tutela judicial efectiva (del art. 47 CDFUE) el art. 698.1 LEC en cuanto dicho precepto impide en cualquier caso, al juez que conoce del procedimiento ordinario por nulidad del título ejecutivo, suspender cautelarmente el procedimiento de ejecución hipotecaria basado en ese mismo título que se reputa nulo. Pues bien, el TJUE aclaró primero que resolvía mediante Auto en virtud del art. 53.2 de su Reglamento de Procedimiento (que así lo prevé cuando el TJUE sea manifiestamente incompetente para conocer de un asunto o cuando una petición sea manifiestamente inadmisible — apartado 20-) para, acto seguido, declararse manifiestamente incompetente para resolver las cuestiones planteadas, en la medida en que «cuando una situación jurídica no está comprendida en el ámbito de aplicación del Derecho de la Unión, el Tribunal de Justicia no tiene competencia para conocer de ella, y las disposiciones de la Carta eventualmente invocadas no pueden fundar por sí solas tal competencia» (apartado 25).

56 Así, no se admiten efectos autónomos del derecho a la vivienda de ese art. 34 CDFUE si no entra en juego la citada Directiva: en el apartado 49 del Auto se sostiene que «en contra de lo señalado por ese órgano jurisdiccional, esa disposición de la Carta no garantiza el derecho a la vivienda sino el «derecho a una ayuda social y a una ayuda de vivienda» en el marco de las políticas sociales basadas en el artículo 153 TFUE». 
actores políticos nacionales ${ }^{57}$; de la misma manera que, mutatis mutandis, se acude con frecuencia en el ámbito interno a la justicia constitucional «como sucedáneo maltratado de la reforma constitucional» ${ }^{58}$.

En resumen, nos encontramos ante resoluciones del TJUE pronunciadas en el panorama de la crisis económica y financiera (y de la subcrisis de las hipotecas y el drama de los desahucios) de gran impacto mediático relacionadas con el deficitario desarrollo constitucional del derecho a la vivienda que han sido destacadas, en parte con razón, pero en parte con exageración. Puesto que, a decir verdad, esos apuntes jurisdiccionales en modo alguno llegan, más allá del estudio del caso concreto, a paliar una situación general provocada por una legislación que, sin lugar a dudas hasta el estallido de la burbuja inmobiliaria, ha estado más centrada en la calidad de la edificación que en el propio acceso a la vivienda ${ }^{59}$.

En lo que concierne a la otra estrategia procesal anticipada en el presente bloque (la formulación inadecuada en cuanto al momento elegido para evitar una compleja prejudicialidad), la referencia viene marcada por la STJUE de 19 de septiembre de 2013 (Betriu Montull, asunto C-5/12), en la que se dirimió la diferencia de trato entre madre trabajadora por cuenta ajena y padre trabajador por cuenta ajena en el disfrute del derecho a un permiso después del nacimiento de un hijo. La concreta petición de decisión prejudicial fue formulada por el Juzgado de lo Social n. ${ }^{\circ} 1$ de Lleida en el marco de un litigio entre el Sr. Betriu Montull y el Instituto Nacional de la Seguridad Social (INSS), en relación con la negativa a concederle una prestación por maternidad debido a que la madre de su hijo no estaba afiliada al sistema público de seguridad social; tal denegación se basaba en el art. 133bis) de la Ley General de Seguridad Social en conexión con el art. 48.4 del Estatuto de los Trabajadores, de los que se desprende que el derecho al descanso es originario de la madre incluida en algún régimen público de seguridad social, y que, en la maternidad biológica, ese derecho para el padre no es propio, autónomo e independiente del de la madre, sino que, necesariamente, surge por derivación de este último.

A este respecto, el Juzgado remitente planteaba si, al margen del período de descanso obligatorio de seis semanas para la madre inmediatamente después del

57 Precisamente a propósito de esas sentencias del TJUE sobre familias «hipotecadas», ha podido reflexionarse que «desde el euroescepticismo se nos puede decir que el Tribunal de Justicia de la Unión no tiene, en el día a día, capacidad bastante para resolver los problemas que atañen a nuestros ciudadanos. Y ello es verdad. Pero aún es más cierto que en Bruselas se acordó ampliar su número de salas, para empezar con doce nuevos magistrados, sin que el nombramiento se haya podido hacer por desacuerdos entre ciertos políticos nacionales, quizá poco deseosos de verse sometidos a controles jurídicos independientes»: Alzaga Villaamil, O.: «Invitación, desde el realismo, al estudio de la construcción política de Europa», Teoría y Realidad Constitucional, n. ${ }^{\circ}$ 32, 2013, p. 96.

58 Cruz Villalón, P.: «Legitimidad 'activa' y legitimidad 'pasiva' de los Tribunales Constitucionales en el espacio constitucional europeo», Teoría y Realidad Constitucional, n. ${ }^{\circ} 33,2014$, p. 149.

59 Dicha crítica en Díaz Delgado, J.: «Aspectos administrativos de la LOE. Las Administraciones Públicas ante el proceso edificatorio», en VV.AA.: Estudio sobre la nueva Ley de ordenación de la edificación, Colección «Estudios de Derecho Judicial», n. ${ }^{\circ}$ 27, Madrid, CGPJ, Madrid, 2000, p. 63. Léase en el mismo sentido crítico García Macho, R.: «Los derechos sociales y el derecho a una vivienda», Revista Catalana de Dret Públic, n. 38 (monográfico sobre Derecho a la vivienda, urbanismo y cobesión social), 2009, pp. 67-95. 
parto (en donde la diferencia de trato o estaría justificada por la protección de la madre por el hecho del alumbramiento), en lo que atañe en cambio al período de diez semanas posterior a esas seis semanas de descanso obligatorio para la madre, la situación del padre y la de la madre trabajadores por cuenta ajena serían comparables y, por tanto, el trato diferente (configuración del derecho del padre como derivado del de la madre) no estaría justificado bajo el ángulo del permiso parental y como medida de conciliación de la vida familiar y laboral, por lo que sería discriminatorio.

La visualización de semejante controversia, en clave de doble prejudicialidad, quedaba reflejada en la propia STJUE de 19 de septiembre de 2013, tanto en el plano procedimental (apartados 31 a 39), como en el terreno sustancial (apartados 24 y 25). Por lo que se refiere a este segundo ámbito, se recuerda que el citado Juzgado de Lleida había planteado al TC una cuestión de inconstitucionalidad relativa al art. 48.4 del Estatuto de los Trabajadores, que fue resuelta mediante STC 75/2011, de 19 de mayo, desestimando la cuestión al considerar que la referida diferencia de trato no vulneraba el principio de igualdad del art. 14 CE ni la protección de la familia y de la infancia del art. 39 CE en combinación conel disfrute del sistema de seguridad social del art. 41 CE. Sin embargo, el Juzgado «alberga dudas acerca de la conformidad del art. 48.4 del Estatuto de los Trabajadores con el Derecho de la Unión» (apartado 26), dudas que reciben una respuesta desestimatoria asimismo por parte del TJUE con apoyo en las normas europeas de referencia $^{60}$. Sin duda, la concurrencia de soluciones europea y constitucional venía asimismo favorecida por la actitud de sinergia mostrada en la STC 75/2011, que se hizo eco de la jurisprudencia comunitaria precedente en la materia ${ }^{61}$.

\section{FORMULACIONES DOMÉSTICAS CON ARRIESGADA PREGUNTA INNECESARIA}

Las estrategias procesales de órganos jurisdiccionales nacionales que encuentran su espacio en el presente apartado tienen que ver con uno de los ámbitos sustanciales que arroja mayores pronunciamientos prejudiciales del TJUE, es decir, la política social; y el carácter arriesgado e innecesario de las formulaciones domésticas guarda conexión con las soluciones, normalmente más específicas, de la jurisprudencia del Comité Europeo de Derechos Sociales (CEDS).

60 Las Directivas 92/85/CEE del Consejo, de 19 de octubre de 1992, relativa a la aplicación de medidas para promover la mejora de la seguridad y de la salud en el trabajo de la trabajadora embarazada, que haya dado a luz o en período de lactancia (Décima Directiva específica con arreglo al apartado 1 del artículo 16 de la Directiva 89/391/CEE), y 76/207/CEE del Consejo, de 9 de febrero de 1976, relativa a la aplicación del principio de igualdad de trato entre hombres y mujeres en lo que se refiere al acceso al empleo, a la formación y a la promoción profesionales, y a las condiciones de trabajo.

61 Véanse las referencias a las correspondientes sentencias del TJUE en los FFJJ 7 y 8 de la STC $75 / 2011$. 
Ese riesgo, de entrada, se podía haber verificado con motivo de la STJUE de 15 de enero de 2014 (Association de médiation sociale, AMS, asunto C-176/2012), que trae su causa de la petición de decisión prejudicial formulada por la Corte de Casación francesa en el marco de un litigio entre la AMS y diversos agentes sindicales acerca de la sujeción de la constitución de órganos representativos de personal a ciertos umbrales de trabajadores empleados; ello a la luz de la Directiva 2002/14/CE del Parlamento Europeo y del Consejo, de 11 de marzo de 2002, por la que se establece un marco general relativo a la información y a la consulta de los trabajadores en la Comunidad Europea, y del derecho fundamental a la información y consulta de los trabajadores en el seno de la empresa del art. 27 CDFUE.

Los avatares procesales nacionales vinieron precedidos de una controvertida prejudicialidad ante el Consejo Constitucional (una cuestión prioritaria de constitucionalidad que fue resuelta por éste el 29 de abril de 2011 declarando que el artículo L. 1111-3 del Código de trabajo era conforme con la Constitución francesa $)^{62}$, cuya decisión no fue curiosamente acatada por el órgano jurisdiccional de primera instancia (el Tribunal de Instancia de Marsella, que decidió descartar la aplicación de ese canon constitucional dando primacía al Derecho de la UE). Posteriormente, en vía casacional, la Corte de Casación gala formuló la cuestión prejudicial que dio origen a la STJUE de 15 de enero de 2014.

Ésta venía sustancialmente a corroborar la posición del tribunal de instancia desautorizando el canon establecido por el Consejo Constitucional (apartado $29)^{63}$, efectuando contrariamente a renglón seguido un salto cualitativo nada desdeñable al descartar no sólo el efecto directo entre particulares de la Directiva 2002/14 (apartados 30 a 41) ${ }^{64}$ sino, de manera más decepcionante aún, ese mismo efecto horizontal del art. 27 CDFUE $^{65}$.

Con tal proceder, el TJUE no sólo se apartaba de la razonable $-\mathrm{y}$, a mi entender, acertada - lectura combinada de dicha Directiva y del art. 27 CDFUE incluida en las Conclusiones del Abogado General Pedro Cruz Villalón ${ }^{66}$ (autorizada opi-

62 Así se recoge en los apartados 17 y 18 de la STJUE de 15 de enero de 2014.

63 A tenor del apartado 29 de la STJUE de 15 de enero de 2014, «se ha de concluir que el artículo 3 , apartado 1, de la Directiva 2002/14 debe interpretarse en el sentido de que se opone a una disposición nacional como el artículo L. 1111-3 del Código de trabajo, que excluye a los trabajadores titulares de contratos de trabajo apoyados del cómputo del personal de la empresa para la determinación del número de trabajadores requerido legalmente para constituir órganos de representación del personal».

64 El fallo de la STJUE de 15 de enero de 2014 dispone que el art. 27 CDFUE, «por sí solo o en conjunción» con la Directiva 2002/14/CE «deben interpretarse en el sentido de que, cuando una disposición nacional de transposición de esa Directiva, como el artículo L. 1111-3 del Código de trabajo francés, es incompatible con el Derecho de la Unión, ese artículo de la Carta no puede ser invocado en un litigio entre particulares para excluir la aplicación de esa disposición nacional».

65 LAZZERINI, N.: «Causa C-176/12. Association de médiation sociale: la Corte di giustizia rompe (...in parte) il silenzio sugli effetti orizzontali della Carta», en Diritti comparati. Comparare i diritti fondamentali in Europa, lunes 3 de marzo de 2014, http://www.diritticomparati.it/2014/03/causa-c-17612-association-de-m\%C3\%A9diation-sociale-la-corte-di-giustizia-rompe-in-parte-il-silenzio-sugl.html (visitado 13 de diciembre de 2016).

66 Apartados 97 y 98 de las Conclusiones de Pedro Cruz Villalón. 
nión saludada por la doctrina ${ }^{67}$ ) sino, asimismo, del efecto útil del equivalente art. 21 de la Carta Social Europea revisada de $1996^{68}$. A este último respecto, en sus Conclusiones publicadas en enero de 2015, el CEDS condenó a Francia por los mismos motivos que los expresados en el apartado 29 de la STJUE de 15 de enero de 2014, pero lógicamente por disconformidad del art. L. 1111-3 del Código de Trabajo con el citado art. 21 de la Carta Social ${ }^{69}$.

La lectura que, en mi opinión, se desprende de cuanto antecede es clara: primeramente, el Tribunal de Instancia de Marsella podría haber inaplicado el controvertido art. L. 1111-3 del Código laboral (previamente declarado conforme a la Carta Magna francesa por el Consejo Constitucional), no tanto acudiendo a los principios de primacía y efecto directo del Derecho de la UE, sino ejerciendo el control de convencionalidad con apoyo en el art. 21 de la Carta Social; y, en segundo término, la propia Corte de Casación podría haber omitido el innecesario planteamiento de la cuestión prejudicial comunitaria, ejerciendo ese mismo control de convencionalidad para alcanzar la solución de aplicación horizontal de dicho art. 21 y evitando así el restrictivo fallo en tal sentido del TJUE. Semejante línea argumental se revela tanto más practicable en Francia cuanto que, en nuestro país vecino, el control de convencionalidad se ha venido ejerciendo con naturalidad ante la ausencia de la cuestión de inconstitucionalidad hasta hace pocos años ${ }^{70}$. Y, de hecho, tanto la Corte de Casación como instancias jurisdiccionales inferiores francesas cuentan ya con experiencia en materia de control de convencionalidad con apoyo en la Carta Social y en la jurisprudencia del CEDS en ámbitos como las guardias localizadas («périodes d'astreinte») o el sistema de remuneración a tanto alzado («forfait en jours» $)^{71}$.

Lo recién expuesto conduce a una reflexión similar con relación a España sobre la base de otro pronunciamiento reciente de la Justicia comunitaria,

67 Entre otros, por Millán Moro, L.: «TJUE-Sentencia del Tribunal de Justicia de 15.1.2014 (Gran Sala) - Association de Médiation Sociale, Asunto C-176/12. Eficacia directa versus primacía», Revista de Derecho Comunitario Europeo, n. ${ }^{\circ}$ 49, 2014, p. 1042; WARD, A.: «Art. 51 - Scope», en The EU Charter of Fundamental Rights. A Commentary (Eds. Peers, S., Hervey, T., Kenner, J., and Ward, A.), Oxford, Hart Publishing, 2014, p. 1429; Buffa, F.: I licenziamenti nel Jobs Act e nelle norme internazionali, Milano, Key Editore, 2015, p. 31; o Laulom, S.: «Les seuils d'effectif: une confirmation et une déception», Semaine Sociale Lamy, n. ${ }^{\circ} 1640$ (suplemento del 21 de julio de 2014).

68 Véase asimismo el apartado 52 de las Conclusiones de Pedro Cruz Villalón.

69 Concluye el CEDS: «la exclusión, establecida por el art. L. 111-3 del Código, de los trabajadores titulares de contratos apoyados o tutelados del cálculo del efectivo de la empresa — cálculo necesario para la determinación de los umbrales mínimos que permiten la creación de instituciones representativas del personal que aseguren la información y la consulta de los trabajadores- no es conforme a la Carta» [al art. 21 de la Carta Social Europea revisada].

70 Bon, P.: «La cuestión prejudicial de constitucionalidad en Francia: ¿Solución o problema?», Teoría y Realidad Constitucional, n. ${ }^{\circ} 23,2009$, p. 321.

71 Ilustraciones en MiNÉ, M.: «Le droit du temps de travail à la lumière de la Charte sociale européenne», Semaine Sociale Lamy, 17 de enero de 2011, n. ${ }^{\circ} 1475$, pp. 7 y ss. Léase asimismo, confrontando la Carta Social con el Derecho de la UE, el artículo de Johansson, A.: «Influence sur le droit français de la directive temps de travail 2003/88 (anc. 93/104) et la jurisprudence de la Cour de Justice y afférente (hors congés payés)», Droit Social, n. ${ }^{\circ}$ 9, 2013, pp. 821 y ss. 
concretamente la STJUE de 5 de febrero de 2015 (Nisttabuz Poclava, asunto C-117/14), en donde el Tribunal de Luxemburgo se declaró incompetente para enjuiciar el controvertido contrato de apoyo a emprendedores (un año de período de prueba con posible despido sin preaviso ni indemnización) previsto por el art. 4.3 de la Ley 3/2012, de 6 de julio, de reforma del mercado de trabajo. Una modalidad contractual análoga, introducida con anterioridad en Grecia asimismo por influencia de la Troika, que había sido declarada por el CEDS contraria al art. 4.4 de la Carta Social Europea de 1961 (ratificada por España en 1980) mediante su Decisión de 24 de mayo de 2012 (Reclamación colectiva n. ${ }^{\circ}$ 65/2011).

Reviste interés este asunto, puesto que algunos órganos jurisdiccionales españoles (Juzgados de lo Social) decidieron ejercer el control de convencionalidad descartando la aplicación del art. 4.3 de la Ley 3/2012 al otorgar prevalencia al tratado internacional del Consejo de Europa (al art. 4.4 de la Carta Social) ${ }^{72}$. El interés se ha acentuado, puesto que, incluso tras la STC 119/2014, de 16 de julio (que avala, con una coyuntural argumentación «anticrisis» ${ }^{73}$, la constitucionalidad del art. 4.3 de la Ley 3/2012) ${ }^{74}$, algunos órganos de la jurisdicción social (y no sólo en primera instancia, sino igualmente Salas de lo Social de Tribunales Superiores de Justicia en fase de apelación o suplicación ${ }^{75}$ ) han continuado ejerciendo dicho control de

72 Véanse ejemplos en tal dirección en GONZÁleZ DE LA Rivera i SERRA, X.: «Conversaciones entre la norma internacional y la norma interna: la aplicación por los órganos judiciales», en Los derechos laborales desde la perspectiva de la teoría general del contrato y de la normativa internacional (Coord. FARGAS FERNÁNDEZ, J.), Barcelona, Huygens Editorial, pp. 85-120.

73 Una crítica al respecto en Requejo Rodríguez, P.: «El papel de la crisis económica en la argumentación del Tribunal Constitucional. Comentario a la STC 119/2014», Teoría y Realidad Constitucional, n. ${ }^{\circ}$ 36, 2015, en particular p. 430 y p. 436. Léase asimismo SAntiago Rivera, C.A.: «La duración del período de prueba en la Jurisprudencia Constitucional Española», Revista de Administración Pública, Universidad de Puerto Rico, vol. 47, 2016, pp. 309-364.

74 Paradójicamente, con relación a la toma en consideración de las resoluciones del CEDS, resulta pertinente traer a colación la STC 61/2013, de 14 de marzo, en cuyo FJ 5, con remisión a la jurisprudencia constitucional precedente (entre otras, SSTC 292/2000, de 30 de noviembre, FJ 3, o 136/2011, de 13 de septiembre, FJ 12), en donde se sostiene que «tanto los tratados y acuerdos internacionales, como el Derecho comunitario derivado pueden constituir «valiosos criterios hermenéuticos del sentido y alcance de los derechos y libertades que la Constitución reconoce», valor que se atribuye con fundamento en el art. 10.2 CE, a cuyo tenor, y según hemos destacado en otros pronunciamientos, «las normas relativas a los derechos fundamentales y libertades públicas contenidas en la Constitución deben interpretarse de conformidad con los tratados y acuerdos internacionales sobre las mismas materias ratificados por España (art. 10.2 CE); interpretación que no puede prescindir de la que, a su vez, llevan a cabo los órganos de garantía establecidos por esos mismos tratados y acuerdos internacionales» (STC 116/2006, de 24 de abril, FJ 5; o STC 198/2012, de 6 de noviembre, FJ 9)». La cursiva es mía, pero se entenderá mejor esa toma en consideración de las conclusiones y decisiones del CEDS si se repara en que el propio TC ha acudido en ocasiones como parámetro interpretativo a declaraciones y recomendaciones (por tanto, en tal caso no vinculantes): lo ilustra Alfonso Mellado, C.: Constitución, Tratados internacionales y Derecho del trabajo, Madrid, Fundación 1. ${ }^{\circ}$ de Mayo, 2014, pp. 66-67. Abundando en esa misma línea, López López, J.: «La construcción de derechos sociales: judicialización y aplicación de los Convenios de la OIT», en La aplicación de los convenios de la OIT por los jueces nacionales: el caso español desde una perspectiva comparada (Coords. López López, J., y otros), Albacete, Bomarzo, 2011, p. 15.

75 Por ejemplo, ha ejercido netamente y sin ambages ese control de convencionalidad, la Sala de lo Social del TSJ de Canarias (por ejemplo, sentencias de fecha 28 de enero, 30 de marzo y 18 de abril de 2016 , en los recursos de suplicación, respectivamente, n. ${ }^{\circ} 581 / 2015$, n. $.^{\circ} 989 / 2015$ y n. ${ }^{\circ} 110 / 2016$ ); postura a la que 
convencionalidad $^{76}$. En la doctrina laboralista se ha respaldado con rotundidad ese control de convencionalidad ${ }^{77}$, cuyo ejercicio no habría de plantear mayores problemas a los estudiosos internacionalistas ${ }^{78}$, ni debería escapar a una reflexión seria en sede constitucionalista (doctrinal ${ }^{79}$ y jurisprudencial ${ }^{80}$ ).

Con semejante planteamiento, y siguiendo esta línea argumentativa, es evidente que, de haber decidido el Juzgado de lo Social n. 23 de Madrid ejercer el control de convencionalidad, no habría formulado una cuestión prejudicial ante el TJUE que, a la vista del resultado (la Sentencia Nisttabuz Poclava) se ha revelado innecesaria, pero no exenta de riesgo (si, en vez de declararse incompetente, el TJUE hubiera entrado en el fondo del asunto y generado una respuesta contradictoria con respecto a la previa alcanzada por el CEDS $)^{81}$.

se ha sumado recientemente la Sala de lo Social del TSJ de Castilla y León (Valladolid; sentencia de 26 de septiembre de 2015, recurso de suplicación n. ${ }^{\circ}$ 1527/2016).

76 Además del apoyo en la decisión sobre la Reclamación n. ${ }^{\circ}$ 65/2011 contra Grecia, los órganos jurisdiccionales españoles ya contaron desde enero de 2015 con una conclusión de condena directa contra España, pues el CEDS declaró explícitamente que «el artículo 4, párrafo 3, de la Ley 3/2012 no es conforme al artículo 4.4 de la Carta de 1961».

77 Entre otros, Molina Navarrete, C.: «Reforma laboral y 'Justicia Constitucional': el Tribunal Constitucional ni es 'infalible' ni ya tiene la 'última palabra'. Comentario a la STC 129/2014, de 16 de julio, RI 56032012, interpuesto por el Parlamento de Navarra contra la Ley 3/2012, de 6 de julio, de reforma del mercado de trabajo», RTSS-CEF, n. ${ }^{\circ}$ 377-378, agosto-septiembre 2014, pp. 183-190; asimismo SALCEDo BeltráN, C.: «La aplicabilidad directa de la Carta Social Europea por los órganos judiciales», Trabajo y Derecho, n. ${ }^{\circ} 13$, enero 2016, pp. 27-52. En sentido opuesto, García-Perrote Escartín, I.: «Carta de los Derechos Fundamentales de la Unión Europea, Carta Social Europea y reforma laboral española. A propósito de la duración del período de prueba del contrato de trabajo de apoyo a los emprendedores», Trabajo y Derecho, n. ${ }^{\circ} 15,2016$, pp. 1-27.

78 Sobre la base, entre otros, de los artículos 10.2 y 93 a 96 CE, en conjunción con el artículo 1.5 del Código civil y los artículos 23.3 y 30.1 de la Ley 25/2014, de 27 de noviembre, de Tratados y otros Acuerdos Internacionales: Jimenez GARcíA, F.: «La protección internacional de los derechos sociales y económicos. Avances recientes, técnicas de aplicación y propuestas de reforma constitucional», Revista Europea de Derechos Fundamentales, n. ${ }^{\circ} 25,2015$, p. 54 .

79 Claramente favorable a ese enfoque del control de convencionalidad, JimENA QuESADA, L.: Jurisdicción nacional y control de convencionalidad, Cizur Menor, Aranzadi, 2013; contrario al control «difuso» de convencionalidad, Canosa Usera, R.: El control de convencionalidad, Madrid, Civitas, 2015.

80 De gran interés resulta el voto particular concurrente de Juan Antonio Xiol Ríos (al que se adhieren Adela Asua Batarrita y Fernando Valdés Dal-Ré) formulado a la STC 270/2015, de 17 de diciembre, en donde se afirma que la cuestión del control de convencionalidad «debería ser sometida a una reconsideración más profunda por este Tribunal para evitar determinadas situaciones paradójicas que se plantean en el ordenamiento jurídico español» y con respecto a lo cual «este Tribunal, como máximo intérprete de la Constitución, deberá pronunciarse más fundadamente en algún momento». Y se recapitula así la crítica a esa elusión del control de convencionalidad: «La actual jurisprudencia parece que aboca a que sólo se posibilite el desarrollo de ese control de convencionalidad de manera concreta por parte de los órganos judiciales cuando deba aplicarse la ley que se estime contraria a un tratado internacional a partir de considerarlo una mera cuestión de selección normativa, lo que, en su caso, podría ser impugnado en amparo por la vía del art. 24.1 CE en caso de arbitrariedad o irrazonabilidad. Ahora bien, no deja de resultar paradójico que en el contexto de una creciente propensión al control abstracto de normas con fundamento en razones de seguridad jurídica, el único control abstracto que quede ayuno de cualquier vía de planteamiento sea el control de convencionalidad de las normas con rango de ley que, si no puede ser ejercido por la jurisdicción ordinaria, tampoco este Tribunal está posibilitando que se ejerza a través del recurso de inconstitucionalidad o la cuestión de inconstitucionalidad por la vía de la invocación de los arts. 9.1 o 96 CE».

81 Puesto que dicho Juzgado cuestionaba, directa y concretamente, que el mencionado contrato de trabajo por tiempo indefinido de apoyo a emprendedores infringiría el Derecho de la UE (entre ellos, el art. 30 
La hipótesis de la asimetría no es descartable, puesto que contamos con ejemplos de sintonía ${ }^{82}$, pero también de divergencia ${ }^{83}$. De un lado, el CEDS se ha mostrado sensible a la posible armonización con el Derecho de la UE cuando las normas comunitarias y la jurisprudencia del TJUE van en línea paralela a la Carta Social y a la jurisprudencia del $\mathrm{CEDS}^{84}$, si bien ha descartado en el ámbito social el equivalente a la «doctrina Bosphorus» del TEDH ${ }^{85}$. De otro lado, el TJUE no parece por el momento dispuesto a dotar de mayor fuerza a los derechos sociales fundamentales reconocidos en la $\mathrm{CDFUE}^{86} \mathrm{ni}$ a eventualmente inspirarse en la jurisprudencia del CEDS pese a lo previsto en las Explicaciones del Praesidium anejas a la $\mathrm{CDFUE}^{87}$, a diferencia del $\mathrm{TEDH}^{88}$.

CDFUE) en conexión con la Carta Social Europea de 1961, «infracción que resulta del contenido de una decisión de 23 de mayo de 2012 del Comité Europeo de Derechos Sociales relativa a un contrato griego similar» (apartado 23 de la STJUE Nisttabuz Poclava).

82 Como ejemplo de soluciones concordantes (en materia de cómputo de las «guardias localizadas», no asimilables a período de descanso) pueden verse la Decisión del CEDS de 8 de diciembre de 2004 sobre la Reclamación colectiva n..$^{\circ}$ 22/2003 (Confederación General del Trabajo c. Francia), y la STJUE de 1 de diciembre de 2005 (Abdelkader Dellas, asunto C-14/04); si bien el TJUE ignora la previa decisión del CEDS.

83 Ejemplo de asimetría lo representa el conocido «asunto Laval». Concretamente, en la Decisión del CEDS de fecha 3 de julio de 2013 (de resolución de la Reclamación n. ${ }^{\circ}$ 85/2012, Confederación General del Trabajo de Suecia y Confederación General de directivos, funcionarios y empleados c. Suecia) se analizaron los cambios introducidos en el terreno de la libertad sindical y la negociación colectiva en la legislación sueca tras la sentencia Laval del TJUE (de 18 de diciembre de 2007, asunto C-341/05), alcanzándose una solución divergente.

84 Así, en la Conclusión de enero de 2015 relativa a la contrariedad del art. L. 1111-3 del Código de Trabajo francés con el art. 21 de la Carta Social, el CEDS asume la referencia de los umbrales mínimos establecidos en la Directiva 2002/14/CE y se hace eco explícitamente de las sentencias del TJUE de 18 de enero de 2007 (Confederación General del Trabajo y otros, asunto C-385/05) y de 15 de enero de 2014 (Association de médiation sociale, asunto C-176/12).

85 Stangos, P.: «Les rapports entre la Charte sociale européenne et le Droit de l'Union européenne. Le rôle singulier du Comité européen des Droits sociaux et de sa jurisprudence», Cabiers de droit européen, $\mathrm{n}^{\circ}{ }^{\circ} 2$, 2013 , pp. 319-393 (especialmente, pp. 367 y ss.).

86 Véase la STJUE de 10 de julio de 2014 (Victor Manuel Julian Hernández y otros, asunto C-198/13).

87 Cf. Conclusiones del Abogado General Maciej Szpunar (presentadas el 28 de enero de 2015) en el asunto C-579/13 (P, S c. Commissie Sociale Zekerheid Breda, College van Burgemeester en Wethouders van de gemeente Amstelveen, sobre controles fronterizos y estatuto de los nacionales de terceros países residentes de larga duración a la luz de la Directiva 2003/109/CE). En el apartado 46 de esas Conclusiones, al abordar la «esencia del derecho de reagrupación familiar», anota: «El Tribunal de Justicia no ha tenido ocasión de pronunciarse sobre si la Directiva 2003/86/CE del Consejo, de 22 de septiembre de 2003, sobre el derecho a la reagrupación familiar se opone a que la entrada en el territorio nacional se supedite a la obligación de superar un examen de este tipo. El Comité Europeo de Derechos Sociales consideró que sería contrario al artículo 19, apartado 6, de la Carta Social Europea condicionar la entrada en el territorio nacional o la continuación de la residencia en virtud de la reagrupación familiar a tal obligación (véase documento de trabajo de 15 de julio de 2014 titulado «La relation entre le droit de l'Union européenne et la Charte sociale européenne», apartado 76)». Así, se ha criticado que también en la UE (como en el Consejo de Europa) debería superarse esa indivisibilidad desigual entre derechos civiles y derechos sociales, la desigual toma en consideración del CEDH y de la Carta Social Europea, para que ésta no juegue como mera fuente de inspiración a la baja ni el CEDS sufra una especie de «omisión expiatoria» como la propinada en la CDFUE: BELORGEY, J.M.: «Le Conseil de l'Europe au milieu du gué», Revue administrative, n. ${ }^{\circ} 372,2010$, pp. 625-626.

88 Son numerosas ya las Sentencias del TEDH en las que se hace eco explícitamente de la jurisprudencia del CEDS (entre otras muchas, SSTEDH Sørensen y Rasmussen c. Dinamarca de 11 de enero de 2006), Demir y Baykara c. Turquía de 12 de noviembre de 2008, o Winterstein y otros c. Francia de 17 de octubre de 2013). 
En estas circunstancias, y como quiera que es difícil a corto y medio plazo atisbar una adhesión de la UE a la Carta Social Europea del Consejo de Europa (y, más aún, a rebufo de la ralentización de la paralela adhesión al CEDH tras el Dictamen 2/13 del Pleno del Tribunal de Luxemburgo, de 18 de diciembre de 2014), quizá convenga congratularse del self-restraint ejercido por el TJUE para eludir el factor de riesgo mencionado (Europa social a varias velocidades), a condición de dinamizar la Carta Social del Consejo de Europa como vector básico de referencia en este terreno ${ }^{89}$.

\section{ALGUNOS RETOS: DOBLE PREJUDICIALIDAD Y PREJUDICIALIDAD OMISIVA}

\section{La disciplina de la doble prejudicialidad para evitación de contenciosos paralelos y de potenciales soluciones divergentes}

La polémica sobre una posible doble prejuidicialidad (europea y constitucional) quedó ya planteada en España con motivo de la cuestión de inconstitucionalidad que dio lugar a la STC 65/1990, de 5 de abril ${ }^{90}$, en donde se suscitó frontalmente la concurrencia de ese planteamiento con la potencial formulación de una cuestión prejudicial (por el órgano jurisdiccional ordinario o en su caso por el propio TC) ante el TJUE ${ }^{91}$. La cuestión reviste gran trascendencia, precisamente para evitar un posible canon de constitucionalidad divergente que pueda ofrecer la sensación de un apartamiento de pronunciamientos previos del Tribunal de Luxemburgo en la materia. En la praxis, aunque en este caso no parezca aflorar una divergencia que sea fruto de la disociación del canon de constitucionalidad y del parámetro comunitario europeo ( $y$ conviene subrayar en este sentido que no hubo votos particulares en el seno del TC) el FJ 4 sí evoca una discutible diversidad de enfoques ${ }^{92}$.

\footnotetext{
Así lo recuerda también la Abogada General Juliane Kokott en sus Conclusiones (presentadas el 8 de septiembre de 2005) en el asunto C-540/03 (Parlamento Europeo c. Consejo de la UE apoyado por Alemania y Comisión), sobre la entrada y residencia de hijos menores de edad asimismo en el marco de la Directiva 2003/86/CE. En el apartado 74 de las Conclusiones puede leerse: «hay muchas razones para pensar que el artículo 19, apartado 6, de la Carta Social Europea establece criterios más generosos que los del CEDH para la reunificación familiar de trabajadores migrantes en el Estado de acogida. (...) Además, en sus resoluciones, el Comité Europeo de Derechos Sociales, que vigila la aplicación de la Carta Social Europea, sólo ha aceptado períodos de espera inferiores a un año y ha considerado improcedentes los períodos de espera de tres años o más. Por último, en recientes sentencias el TEDH ha recurrido a las disposiciones de la Carta Social y a la práctica jurisprudencial del citado Comité de interpretación y aplicación del CEDH, especialmente del artículo 8».

89 En esta línea, se ha afirmado que mientras el TEDH y el TJUE se ven «paralizados» por el respeto escrupuloso de sus competencias, el CEDS «se erige en el defensor último de la Europa social», NivARD, Carole: «Un destin divergent: les relations entre l'Union européenne et la Charte sociale européenne», Revue de l'Union Européenne, n. ${ }^{\circ}$ 600, 2016, p. 425.

90 En el mismo sentido, de idéntica fecha, las SSTC 66/1990 y 67/1990.

91 Véase antecedente 3 de la STC 65/1990.

92 A tenor de dicho FJ 4: «Esa referencia a dicha «cuestión prejudicial» (en realidad han sido cinco las cuestiones planteadas con similar objeto ante el Tribunal comunitario europeo por el Tribunal Central de
} 
Dicho lo cual, y pese a la habilitación existente en el Derecho comunitario (art. 267 TFUE), entiendo que no sería impertinente incluir alguna disposición específica sobre la cuestión prejudicial en la Ley Orgánica del Tribunal Constitucional (LOTC), al modo en que se introdujo el art. 4bis) en la Ley Orgánica del Poder Judicial (LOPJ) ${ }^{93}$, matizando si se quiere la redacción para evitar el juego de susceptibilidades derivado de las nociones de supremacía constitucional, primacía europea, etc. ${ }^{94}$. Pues lo fundamental es la fluidez del diálogo evitando divergencias o contradicciones que, en última instancia, resulten nocivas para la credibilidad del sistema global y de una protección optimizada de los derechos fundamentales ${ }^{95}$. Nos encontramos, por tanto, ante una «nueva era de los derechos» que requiere confianza y cooperación entre tribunales, en beneficio del sistema y de la mejor satisfacción de la justicia ${ }^{96}$.

En tal dirección, convendría explicitar en la LOTC aspectos lógicos que quedan confirmados en el Auto 86/2011, de 9 de junio (caso Melloni), como la suspensión de la tramitación del amparo hasta tanto resuelva el TJUE. Pues bien, me parece que, mutatis mutandis, debería preverse expresamente la eventual concurrencia de una cuestión prejudicial formulada por un órgano jurisdiccional ordinario con una cuestión de inconstitucionalidad planteada ante el TC en objetos y ámbitos normativos coincidentes y afectantes a la interpretación y aplicación del Derecho de la UE. Y, en tal caso, tendría que establecerse asimismo la suspensión del proceso de constitucionalidad ante el TC, confiriendo prioridad a la resolución del procedimiento prejudicial ante el TJUE, en aras de un enfoque

Trabajo español), aconseja reseñar, siquiera brevemente, cuál ha sido la respuesta obtenida por las mismas en el ámbito comunitario en que fueron formuladas. Evidentemente, la resolución del Tribunal de Justicia de las Comunidades Europeas no constituye precedente que resuelva, mediante su aplicación automática, la presente duda; (...) se pronuncia sobre una duda suscitada en un plano jurídico diferente, cual es el del Derecho Comunitario Europeo; pero, además, en este supuesto y como ya se ha indicado anteriormente, son otras las decisiones, recaídas en este mismo ámbito constitucional, que deben considerarse como precedente esencial en la resolución del actual proceso constitucional».

93 El art. 4bis) fue introducido en la LOPJ mediante el apartado dos del artículo único de la Ley Orgánica $7 / 2015$, de 21 de julio. Su tenor literal es el siguiente: «1. Los Jueces y Tribunales aplicarán el Derecho de la Unión Europea de conformidad con la jurisprudencia del Tribunal de Justicia de la Unión Europea. 2. Cuando los Tribunales decidan plantear una cuestión prejudicial europea lo harán de conformidad con la jurisprudencia del Tribunal de Justicia de la Unión Europea y, en todo caso, mediante auto, previa audiencia de las partes».

94 Reflexiona al respecto Torres del Moral, A.: «Relaciones entre la Unión Europea y los Estados miembros según el Tratado constitucional europeo», Revista de Derecho Político, n. ${ }^{\circ}$ 65, 2006, p. 102: «Apenas haría falta subrayar lo que es claro: que primacía no equivale exactamente a supremacía. Bien es verdad que, aunque el Tribunal de Justicia europeo ha utilizado preferentemente el primer término, en determinadas ocasiones ha empleado el segundo (como también el primero en el sentido del segundo)».

95 De «integralidad maximizadora» del sistema global de derechos humanos habla BidART CAMPOS, G.J.: «La interpretación del sistema de derechos humanos», Revista del Instituto Interamericano de Derechos Humanos, vol. 19, 1994, pp. 29-31.

96 Cartabia, M.: «Fundamental Rights and the Relationship among the Court of Justice, the National Supreme Courts and the Strasbourg Court», en 50 th Anniversary of the Judgment in Van Gen den Loos, $1963-$ 2013. Conference Proceedings — Luxembourg 13 May 2013, Luxembourg, Court of Justice, 2013, p. 168. 
más amplio y potencialmente armonizador de Derecho constitucional europeo, no siempre ajeno a polémicas y situaciones conflictivas ${ }^{97}$.

La problemática ya se suscitó hace años ante la Jurisdicción Constitucional italiana, que razonablemente siguió dicho criterio $^{98}$. De todos modos, lo deseable es evitar esa concurrencia de procedimientos comunitario y constitucional y, a tal efecto, en Italia ha sido asimismo la Corte Constitucional la que ha brindado unas orientaciones de índole procesal que han determinado la sustancial «auto-marginación» de la propia Corte en materia comunitaria, con el correspondiente realce del papel de la jurisdicción ordinaria. Con tal espíritu, cuando se verifique esa «doble prejudicialidad» (esto es, que la duda interpretativa referente a la norma comunitaria europea entre a formar parte de los elementos del juicio de constitucionalidad), el órgano jurisdiccional ordinario debe pedir previamente la intervención del TJUE y sólo sucesivamente la de la Corte Constitucional pues, en otro caso, la ausencia de remisión previa al Tribunal de Luxemburgo constituirá un motivo de inadmisibilidad de la cuestión de inconstitucionalidad ${ }^{99} ; \mathrm{y}$, cabalmente, cuando haya mediado esa preliminar actuación del TJUE, devendrá inútil en la praxis que se plantee sucesivamente una cuestión de legitimidad constitucional ante la Alta Corte italiana ${ }^{100}$.

Estimo que el modelo italiano resulta útil a efectos comparados. En el caso francés, la cuestión no ha sido tan claramente afrontada por el Consejo Constitucional tras la introducción de la cuestión prioritaria de constitucionalidad; y, por lo demás, esa prioridad se refiere más bien a las relaciones entre ese novedoso control sucesivo de constitucionalidad por parte de la Jurisdicción Constitucional francesa y el —como se apuntó en el apartado anterior - ya tradicional control de convencionalidad operado por los órganos jurisdiccionales ordinarios. Ahora bien, la Corte de Casación francesa sí decidió en 2010 seguir un proceder similar al verificado en Italia, rehusando plantear la cuestión ante el Consejo Constitucional para dar prioridad a un planteamiento prejudicial ante el Tribunal de Luxemburgo, lo que dio lugar a la importante STJUE de 22 de junio de 2010 (casos Aziz Melki y Sélim Abdeli, asuntos acumulados C-188/10 y C-189/10), en cuyo fallo quedó severamente matizado el carácter prioritario conferido por la normativa nacional al procedimiento incidental de control de constitucionalidad ${ }^{101}$, lo que

97 Gordillo Pérez, L.I., y Martinico, G.: Historias del país de las hadas. La jurisprudencia constitucionalizadora del Tribunal de Justicia, Madrid, Civitas/Thomson Reuters (Cuadernos Civitas), 2015, pp. 143 y ss. 98 Véase la Ordenanza (Auto) de la Corte Constitucional n. 206 de 28 de julio de 1976.

99 Passaglia, P. y otros: Corti costituzionali e rinvio pregiudiziale alla Corte di giustizia, ya cit., p. 19: se traen a colación por dichos autores, entre otras las Ordenanzas (Autos) de la Corte Constitucional n. ${ }^{\circ}$ 536/1995, 319/1996, 108/1998, 415/2008 ó 100/2009.

100 Ibidem.

101 Merece la pena transcribir el primer punto dispositivo del fallo de la STJUE Melki: «El artículo 267 TFUE se opone a una normativa de un Estado miembro que establece un procedimiento incidental de control de constitucionalidad de las leyes nacionales, en la medida en que el carácter prioritario de ese procedimiento tenga como efecto impedir, tanto antes de la remisión de una cuestión de constitucionalidad al 
ha llevado a la doctrina a discernir entre un diálogo judicial constructivo y uno forzoso $^{102}$.

Por lo demás, cuando se produzca la vigencia del Protocolo n. ${ }^{\circ} 16$ al CEDH (conocido como «Protocolo del diálogo») y España lo ratifique, la dinámica habrá de ser análoga a la de la sustanciación del recurso de amparo en cuyo marco se genere una cuestión prejudicial, pese a que la sentencia prejudicial del TJUE sea vinculante y la opinión consultiva del TEDH no lo sea. Efectivamente, la eventual consulta al TEDH en virtud del Protocolo n. ${ }^{\circ} 16$ en principio sólo se producirá en el contexto de un recurso de amparo y, aunque la opinión del TEDH no revista obligatoriedad, debería asumirse como tal pues, de lo contrario, tras el agotamiento de la vía judicial previa ante el propio TC, éste se vería desautorizado en Estrasburgo tras la correspondiente demanda individual ${ }^{103}$.

Como propuesta de lege ferenda, considero que la ubicación sistemática de esas nuevas disposiciones podría ser el art. 3 LOTC, de tal forma que la actual redacción pasaría a ser un primer apartado. Me permito proponer entonces estos otros dos apartados: uno segundo que estableciera que «Cuando el Tribunal Constitucional decida formular una cuestión prejudicial ante el Tribunal de Justicia, recabar una opinión consultiva del TEDH en virtud del Protocolo n. 16 u otro tipo de consulta ante otra instancia internacional de protección de derechos bumanos, lo hará mediante auto con suspensión del proceso constitucional y previa audiencia de las partes»; y otro tercero que dispusiera que «En caso de concurrencia de una cuestión prejudicial planteada por otros órganos jurisdiccionales españoles con una cuestión de inconstitucionalidad que contenga objeto análogo y normativa interpuesta coincidente de la UE, se suspenderá la tramitación de ésta hasta tanto aquélla sea resuelta por el Tribunal de Justicia. Por otra parte, cuando la cuestión de inconstitucionalidad introduzca normativa de la UE como parte del juicio de constitucionalidad, el Tribunal Constitucional declarará la inadmisión si antes no ha sido sometida con carácter prejudicial ante el Tribunal de Justicia».

órgano jurisdiccional nacional competente para ejercer el control de constitucionalidad de las leyes como, en su caso, después de la resolución del citado órgano sobre dicha cuestión, que todos los demás órganos jurisdiccionales nacionales ejerzan su facultad o cumplan su obligación de plantear cuestiones prejudiciales al Tribunal de Justicia. En cambio, el artículo 267 TFUE no se opone a dicha legislación nacional, siempre que los demás órganos jurisdiccionales nacionales sigan estando facultados: — para plantear al Tribunal de Justicia toda cuestión prejudicial que consideren necesaria, en cualquier momento del procedimiento que estimen apropiado, e incluso una vez finalizado el procedimiento incidental de control de constitucionalidad, — para adoptar toda medida necesaria para asegurar la tutela judicial provisional de los derechos conferidos por el ordenamiento jurídico de la Unión, y — para dejar inaplicada, una vez finalizado ese procedimiento incidental, la disposición legislativa nacional controvertida si la consideran contraria al Derecho de la Unión. Incumbe al tribunal remitente verificar si la legislación nacional controvertida en los asuntos principales puede interpretarse conforme a esas exigencias del Derecho de la Unión».

102 Sarmiento Ramírez-Escudero, D.: «La question prioritaire de constitutionnalité et le droit européen: L'arrêt Melki: esquisse d'un dialogue des juges constitutionnels et européens sur toile de fond française», Revue trimestrielle de droit européen, vol. 46, n. ${ }^{\circ}$ 3, 2010, pp. 588 y ss.

103 Así lo advirtió el Ex Presidente del TEDH: Discours du Président Dean Spielmann; Séminaire Tribunal constitutionnel, Madrid, 22 mai 2015; accesible en: http://www.echr.coe.int/Documents/Speech_20150522_ OV_Spielmann_Tribunal_constitutionnel_Madrid_FRA.pdf (visitado el 29 de agosto de 2016), p. 7. 
La propuesta de disciplinar la doble prejudicialidad, en suma, se comprende mejor cuando se acude a planteamientos de cuestiones de inconstitucionalidad por parte de órganos jurisdiccionales nacionales que parecen buscar una estrategia de confrontación por parte de la Jurisdicción Constitucional nacional frente al TJUE, y ello tanto si se trata del Tribunal Supremo (por ejemplo, STC $231 / 2015$, de 5 de noviembre $)^{104}$ como de los demás órganos jurisdiccionales ordinarios (verbigracia, STC 100/2012, de 8 de mayo de 2012) ${ }^{105}$.

\section{El reverso de los planteamientos dudosos: la reprochable omisión}

Si hasta ahora he criticado los planteamientos susceptibles de ser catalogados como más que dudosos por acción, no menos crítica (e incluso reproche en algunos supuestos) merecen aquellos planteamientos omisivos (la no formulación de una pertinente, o incluso obligatoria, cuestión prejudicial ante el TJUE) que provocan una distorsión en la correcta articulación de los diversos estándares normativos y niveles de protección de derechos fundamentales. Por supuesto, resulta más complejo localizar esos enfoques omisivos que aquellos otros que ya han dado cuerpo a decisiones prejudiciales del TJUE; si bien, como se verá a continuación, algunas de esas omisiones han llegado indirectamente a Luxemburgo, desde donde se ha pronunciado la correspondiente amonestación (y aun reprimenda).

Corresponde, pues, cuando menos ejemplificar un comportamiento omisivo que no haya llegado al TJUE pese a que, según mi criterio, se imponía la formulación de la cuestión prejudicial, así como algún otro en el que el TJUE sí ha tenido la oportunidad de explayarse con tono recriminatorio. No sin antes advertir que la crítica doctrinal desempeña en este ámbito una función primordial e inductora para la corrección futura de tales omisiones, tanto más cuanto que algunos remedios correctores se han mostrado polémicos o complejos (pensemos

104 La STC 231/2015, trae su causa de la cuestión de inconstitucionalidad n. ${ }^{\circ}$ 1066-2012 planteada por la Sala de lo Contencioso-Administrativo del Tribunal Supremo. En el FJ 7 se recuerda «la cita que el Auto de planteamiento hace, sin ulterior glosa o desarrollo específicos, de la Sentencia de 18 de octubre de 2011, del TJUE, en el asunto Boxus c. Région wallone, resolución a la que, por lo demás, nos hemos referido en la STC 129/2013, de 4 de junio»; tal vez habría resultado más deferente plantear antes la cuestión prejudicial ante el TJUE.

105 La STC 100/2012 tiene su origen en la cuestión de inconstitucionalidad n. ${ }^{\circ}$ 3741-2001 planteada por Sala de lo Contencioso-Administrativo del TSJ de Canarias. En el FJ 7 puede leerse: «Argumenta el órgano judicial que de los arts. 31.3 y 133.1 CE deriva que son el Estado, las Comunidades Autónomas y las corporaciones locales quienes ostentan potestad tributaria y sin embargo con las normas cuestionadas se produce, a su juicio, una abdicación del Estado español del ejercicio de su potestad originaria en materia tributaria al permitir a las instituciones comunitarias, no ya establecer y regular los tributos propios del Estado, sino decidir la pervivencia de barreras fiscales entre diversas partes del territorio nacional español», lo cual «obliga a este Tribunal a precisar» la posible afectación de este ámbito por el al alcance de los arts. 93 y 96 CE, de manera que la concreta integración europea «no ha supuesto, como sostiene el órgano judicial, una abdicación — contra constitutione - del Estado español del ejercicio de sus competencias tributarias», concluyendo la desestimación de la cuestión de inconstitucionalidad. 
en la vía interpuesta de la tutela judicial efectiva a través del recurso de amparo ante el TC en el caso de España ${ }^{106}$ o incluso ante el TEDH ${ }^{107}$ ).

Con tales premisas, el primer ejemplo de comportamiento omisivo viene dado por la STS (Sala de lo contencioso-administrativo, Sección 2.. ) de 19 de noviembre de 2012 (recurso de casación en interés de ley n. ${ }^{\circ}$ 1215/2011) mediante la que se rectifica la doctrina del «tiro único» que venía aplicándose durante años por las Salas de lo Contencioso-Administrativo de los Tribunales Superiores de Justicia en el ámbito tributario (no posibilidad para la Administración tributaria de reiterar liquidaciones si ha incurrido en motivos formales o materiales), como posición más garantista de los derechos fundamentales de la ciudadanía (como contribuyente y como justiciable $)^{108}$, especialmente con apoyo en la seguridad jurídica (art. 9.3 CE) y en la tutela judicial efectiva (art. $24 \mathrm{CE})^{109}$.

El giro operado por el Tribunal Supremo (conocido como «doble o múltiple cartucho») se decantaba por favorecer la posición de la Administración con un criticable enfoque anticrisis (análisis rigorista e in malam partem) pero, sobre todo, más que dudoso en cuanto al respeto de los parámetros constitucionales y europeos en la materia ${ }^{110}$.

106 Véase STC 58/2004, de 19 de abril. Un interesante comentario a dicho pronunciamiento en UGARTEMENDiA ECEIZABARRENA, J.I.: «El recurso prejudicial (234 TCE) como cuestión de amparo. (A propósito de la STC 58/2004, de 19 de abril de 2004, que otorga el amparo frente a una vulneración del art. 24 CE originada por incumplimiento de la obligación de plantear la cuestión prejudicial comunitaria)», Civitas. Revista Española de Derecho Europeo, n. ${ }^{\circ}$ 11, 2004, pp. 441-474. Con anterioridad, véase el trabajo de FrAILE Ortiz, M.: «Negativa del juez nacional a plantear una cuestión prejudicial ante el Tribunal de Justicia de las Comunidades Europeas», Civitas. Revista Española de Derecho Europeo, n. ${ }^{\circ}$ 7, 2003, pp. 433-466.

107 Véase la STEDH Ullens de Schooten y Rezabek. c. Bélgica de 20 de septiembre de 2011, en donde pese a concluir que en el caso de autos no había violación del derecho a un proceso equitativo del art. $6 \mathrm{CEDH}$, tal vulneración podría haberse producido (párrafos 58-63) si el órgano jurisdiccional interno no hubiera motivado la negativa a formular la cuestión prejudicial ante el TJUE.

108 Este es el fallo de la controvertida Sentencia: «Que debemos estimar sustancialmente el recurso de casación en interés de Ley interpuesto por el Abogado del Estado contra la sentencia de 27 de Octubre de 2010, dictada por la Sala de lo Contencioso Administrativo, Sección Tercera, del Tribunal Superior de Justicia de la Comunidad Valenciana, declarando que es doctrina legal la siguiente: "La estimación del recurso contencioso administrativo frente a una liquidación tributaria por razón de una infracción de carácter formal, o incluso de carácter material, siempre que la estimación no descanse en la declaración de inexistencia o extinción sobrevenida de la obligación tributaria liquidada, no impide que la Administración dicte una nueva liquidación en los términos legalmente procedentes, salvo que haya prescrito su derecho a hacerlo, sin perjuicio de la debida subsanación de la correspondiente infracción de acuerdo con lo resuelto por la propia Sentencia”».

109 Para una crítica, especialmente con apoyo en los principios constitucionales, véase BoscH CHOLBI, J.L.: «Una decisión trascendental del Tribunal Supremo: la Sentencia de 19 de noviembre de 2012, sobre la retroacción de actuaciones por la Administración tributaria», Tribunal Fiscal, n. ${ }^{\circ} 265,2013$, pp. 93-96. Una crítica más reciente a ese «nuevo orden» contrario al «tiro único» en LLORENS SELLÉs, R.: «Los recursos y reclamaciones en vía económico-administrativa», en Comentarios a la Ley General Tributaria al hilo de su reforma (Coord. Bosch Cholbi, J.L.), Madrid, Wolters Kluwer/AEDAF, 2016, p. 360.

110 Es necesario observar que la Sentencia recurrida en casación (como se menciona en el encabezamiento de la STS de 19 de noviembre de 2012) es la previamente pronunciada por el TSJ de la Comunitat Valenciana «en el recurso contencioso-administrativo promovido por Clínica Dental Doctor Faus, S.L., frente a la resolución del Tribunal Económico Administrativo Regional de Valencia de 30 de Abril de 2008, relativa a liquidación por el Impuesto sobre Sociedades, ejercicios 1992 y 1993, y sanción correlativa». Es decir, que 
Ni que decir tiene que el Tribunal Supremo podría haber sometido una cuestión de inconstitucionalidad (con apoyo básico en los citados preceptos constitucionales —arts. 9.3 y $24.1-$ ) antes de resolver ese recurso de casación en interés de ley ${ }^{111}$. Puesto que es muy complejo, además de irrespetuoso en caso de duda, diferir el problema al justiciable para obligarle a acudir a la vía de amparo constitucional, cuyas posibilidades de éxito serían escasas ${ }^{112}$; tanto como ante el TEDH tras del agotamiento de los recursos judiciales nacionales ${ }^{113}$.

Más aún, el Alto Tribunal de la Jurisdicción Ordinaria podría (debería) haber resuelto directamente el recurso de casación corroborando la doctrina del «tiro único» con apoyo en la jurisprudencia comunitaria, especialmente la STJUE de 29 de marzo de 2012 (Ufficio IVA di Piacenza y Belvedere Costruzioni Srl, asunto C-500/10, caso $)^{114}$. Por consiguiente, ni siquiera era preciso que el TS planteara

el debate de fondo del que trae su causa la STS de 19 de noviembre de 2012 se remonta a ejercicios tributarios que datan de dos décadas antes.

111 La doctrina de la STS de 19 de noviembre de 2012 se ha venido reiterando a modo de jurisprudencia anticrisis, verbigracia, en la STS de 29 de septiembre de 2014 (recurso n. ${ }^{\circ}$ 1014/2013), conociendo ciertas matizaciones (para que la problemática reiteración se produzca con mayor celeridad en el marco de la ejecución de las sentencias contencioso-administrativas, en lugar de articular una nueva vía económica administrativa) en la más reciente STS de 15 de junio de 2015 (recurso n. ${ }^{\circ}$ 1551/2014).

$112 \mathrm{La}$ experiencia muestra que resulta casi infranqueable el filtro de la admisibilidad con el asidero formal y exclusivo del art. $24 \mathrm{CE}$, en la medida en que el debate constitucional sobre la legalidad tributaria se ha encauzado preferentemente por la vía del control abstracto de constitucionalidad a la luz de los preceptos constitucionales que tienen que ver con el principio de justicia del sistema tributario (art. 31.1 CE) o con el principio de reserva de ley en el establecimiento de los tributos y sus elementos esenciales (art. 133 CE): véanse, por ejemplo, las SSTC 73/2011, de 19 de mayo, o 44/2015, de 5 de marzo.

113 Sobre esas dificultades en el plano procedimental, léase SánChEz Patrón, J.M.: «Las condiciones de admisibilidad de las demandas individuales ante el Tribunal Europeo de Derechos Humanos: ¿Un logro en riesgo?», Ordine internazionale e diritti umani, 2014, pp. 284-303. En el terreno sustancial, acúdase a las diversas contribuciones incluidas en García Berro, F. (Dir.): Derechos fundamentales y hacienda pública. Una perspectiva europea, Cizur Menor, Civitas, 2015.

114 Dicha STJUE de 20 de enero de 2012 ofrece una meridiana respuesta directa a la cuestión planteada en el marco de un litigio sobre recaudación del IVA y terminación de procedimientos de exigencia tributaria debido a su larga duración, debiendo prevalecer la efectividad del derecho fundamental a la tutela judicial dentro de un plazo razonable frente y pese a la necesidad de asegurar la eficiencia en la percepción de los recursos de la UE. En particular, en el fundamental apartado 23 de la ratio decidendi el TJUE afirma de modo contundente: «la necesidad de garantizar que los recursos de la Unión se perciban de forma eficaz no puede ir en contra del respeto del principio del plazo razonable que, con arreglo al artículo 47, párrafo segundo, de la CDFUE, se impone a los Estados miembros cuando éstos aplican el Derecho de la Unión y cuya protección se impone igualmente en virtud del artículo 6, apartado 1, del CEDH». Realmente, el fallo del TJUE adopta una solución garantista, y no meramente recaudatoria o «anticrisis», al dotar de vigencia a la CDFUE y perseguir asimismo una loable convergencia del estándar de la UE con el del Consejo de Europa (el CEDH), en estos términos: Las disposiciones de la Sexta Directiva «deben interpretarse en el sentido de que no se oponen a la aplicación, en materia del impuesto sobre el valor añadido, de una disposición nacional excepcional, como la controvertida en el litigio principal, que establece la terminación automática de los procedimientos pendientes ante el órgano jurisdiccional tributario de casación cuando dichos procedimientos se iniciaron mediante un recurso interpuesto en primera instancia más de diez años — en la práctica más de catorce años — antes de la entrada en vigor de la citada disposición y se desestimaron las pretensiones de la Administración tributaria en las dos primeras instancias, terminación automática en virtud de la cual la resolución de segunda instancia adquiere fuerza de cosa juzgada y se extingue el crédito reivindicado por la Administración tributaria». 
la cuestión prejudicial en dicho caso ${ }^{115}$, por cuanto las liquidaciones controvertidas contaban con el escollo de referirse a un tributo (impuesto de sociedades) no estrictamente regulado por el Derecho de la Unión (lo que hubiera dificultado la invocación de la CDFUE a la luz de su art. 51).

Una vez dictada la STS de 19 de noviembre de 2012, los demás órganos jurisdiccionales ordinarios quedaban invitados a puentearle sometiendo una cuestión prejudicial ante el TJUE (con apoyo en el citado caso Belvedere) en un litigio sobre aplicación de normas comunitarias (por ejemplo, el IVA); bajo tal óptica, el Tribunal Supremo habría quedado como una especie de «free-lance» del Derecho comunitario, desfigurando la conocida como «doctrina Cilfit» ${ }^{116}$.

Por otra parte, semejante actitud de puenteo vendría avalada por la Justicia comunitaria en este tipo de situaciones: por ejemplo, en la reciente STJUE de 8 de noviembre de 2016 (Atanas Ognyanov, asunto C-554-14), en donde se reprocha al órgano jurisdiccional remitente que «no puede, en el litigio principal, considerar válidamente que se encuentra imposibilitado para interpretar la norma nacional de que se trata de conformidad con el Derecho de la Unión, por el mero hecho de que dicha norma ha sido interpretada por Tribunal Supremo de Casación en un sentido que no es compatible con ese Derecho» (apartado 69), correspondiendo a dicho órgano jurisdiccional remitente garantizar la plena eficacia del Derecho de la UE «dejando inaplicada en caso de necesidad, de oficio, la interpretación adoptada» por el Tribunal Supremo no compatible con el canon europeo (apartado 70). De todas formas, la cuestión no es sencilla ni ajena a ciertos recelos, como lo acredita que el Tribunal Supremo español siga replanteándose su papel a propósito del «acto claro» ${ }^{117}$ de la doctrina $«$ Cilfit» ${ }^{118}$.

115 En otros ámbitos, el TS español (la propia Sala de lo Contencioso-Administrativo) sí se ha mostrado más abierto a la recepción del Derecho europeo y al eventual planteamiento de la cuestión prejudicial: como ejemplo reciente, véase la STJUE de 9 de julio de 2015 (Regojo Dans, asunto C-177/14).

116 Sarmiento Ramírez-Escudero, D.: «Los 'Free-Lance' del Derecho comunitario: la desfiguración de la doctrina CILFIT», Estudios de Derecho Judicial, n. ${ }^{\circ}$ 95, 2006 (Monográfico dedicado a La articulación entre el Derecho comunitario y los Derechos nacionales: algunas zonas de fricción), pp. 371 y ss. Se trata de la Sentencia del Tribunal de Luxemburgo de 6 de octubre de 1982 (Cilfit, asunto 283/81), en donde se falla «en el sentido de que un órgano jurisdiccional cuyas decisiones no son susceptibles de ulterior recurso judicial de Derecho interno, cuando se suscita ante él una cuestión de Derecho comunitario, ha de dar cumplimiento a su obligación de someter dicha cuestión al Tribunal de Justicia, a menos que haya comprobado que la cuestión suscitada no es pertinente o que la disposición comunitaria de que se trata fue ya objeto de interpretación por el Tribunal de Justicia o que la correcta aplicación del Derecho comunitario se impone con tal evidencia que no deja lugar a duda razonable alguna; la existencia de tal supuesto debe ser apreciada en función de las características propias del Derecho comunitario, de las dificultades particulares que presenta su interpretación y del riesgo de divergencias de jurisprudencia en el interior de la Comunidad».

117 Para discernir el alcance de las nociones de «impertinencia», «acto aclarado», «acto claro» y otras matizaciones («acto evidente») como excepciones a la obligación de remisión judicial, véase Morcillo Moreno, J.: «El planteamiento de la cuestión prejudicial comunitaria a la luz de la jurisprudencia europea y constitucional: ¿Facultad o deber?», Revista de Administración Pública, n. ${ }^{\circ} 185,2011$, pp. 227-262 (en especial, pp. 232 y 233).

$118 \mathrm{Al}$ respecto, véase la reciente STS (Sala de lo Penal, Sección 1. ${ }^{\text {) }}$ n. ${ }^{\circ} 457$ de 26 de mayo de 2016 (recurso de casación, por infracción de ley, n. ${ }^{\circ}$ 10095/2016), en donde se sostiene (FJ 1): «que determinados 
Para concluir el presente apartado, ilustraré la segunda actitud omisiva objeto de sanción por parte del TJUE en un supuesto que implicó asimismo a España. Se trata de la STJUE de 12 de noviembre de 2009 (Comisión c. España, asunto C-154/08), que tiene su origen en el recurso por incumplimiento interpuesto por la Comisión Europea al denunciar que en nuestro país los servicios prestados a una Comunidad Autónoma por los Registradores de la Propiedad, en su condición de liquidadores titulares de una Oficina Liquidadora de Distrito Hipotecario, no estaban sujetos al IVA. Ello derivaba de la doctrina sentada por el Tribunal Supremo español. Y, sobre este punto, el TJUE ya advertía que contra las resoluciones de la alta jurisdicción ordinaria española en materia de IVA no cabía recurso alguno y, pese a todo, «no planteó una cuestión prejudicial con arreglo al art. 234 TCE [actual art. 267 TFUE] relativa a la interpretación de la Sexta Directiva y su aplicación a las actividades de los registradores-liquidadores» (apartado 34).

Lo cierto es que la propia Comisión Europea incidió en dicho aspecto, destacando «que la sentencia del Tribunal Supremo resulta de un recurso de casación en interés de la Ley y que dicho órgano jurisdiccional, en el marco del citado recurso de casación, no planteó ninguna cuestión al Tribunal de Justicia acerca de la aplicación de la Sexta Directiva a las actividades de los registradores-liquidadores» (apartado 64). Ante ello, el TJUE no aceptó el pretexto argumentativo del Gobierno español invocando «su dificultad para subsanar el incumplimiento alegado por la Comisión, puesto que éste tiene su origen en la sentencia del Tribunal Supremo» (apartado 124), concluyendo claramente el Tribunal de Luxemburgo que cabe declarar el incumplimiento de un Estado miembro «cualquiera que sea el órgano de dicho Estado cuya acción u omisión ha originado el incumplimiento, incluso cuando se trata de una institución constitucionalmente independiente» (apartado 125).

Por lo demás, para cerrar el presente bloque, conviene aludir a un reciente asunto que pone en conexión la problemática de la potencial doble prejudicialidad con la obligación de plantear la cuestión prejudicial. Se trata de la STJUE de 4 de junio de 2015 (Kernkraftwerke Lippe-Ems GmbH, asunto C-5/14), derivada de la cuestión prejudicial formulada por el Finanzgericht Hamburg (Tribunal en materia tributaria de Hamburgo, Alemania), y en la que éste planteó si el art. 267

\footnotetext{
Magistrados entiendan la conveniencia de plantear cuestión prejudicial o incluso que otro Tribunal la haya formulado, en modo alguno determina la obligatoriedad ni siquiera conveniencia de su planteamiento; y así el TJUE, en su sentencia de 9 de septiembre de 2015, asuntos C-72/14 y C-197/14, ECLI: EU:C:2015:564 (asunto $X$ ), concluye que el hecho de que un tribunal de rango inferior haya sometido una cuestión prejudicial "no impide, por sí sola, al órgano jurisdiccional supremo estimar, una vez efectuado el examen de las condiciones formuladas en la sentencia CILFIT y otros, que se halla en presencia de un acto claro". Como consecuencia, el juez nacional "podría decidir no someter cuestión alguna al Tribunal de Justicia y resolver bajo su responsabilidad” sin que sea necesario "esperar la respuesta del Tribunal de Justicia a la cuestión prejudicial planteada por el órgano inferior” ». En el mismo sentido, la precedente STS (misma Sala y Sección) n. 241 de 29 de marzo de 2016 (recurso de casación, por infracción de precepto constitucional, n. ${ }^{\circ}$ 10726/2015).
} 
TFUE facultaba al órgano jurisdiccional de un Estado miembro a plantear al TJUE cuestiones que se susciten en el contexto de la legalidad de una ley nacional en relación con la interpretación del Derecho de la UE también en el caso de que aquel órgano jurisdiccional no sólo tenga, por una parte, dudas acerca de la conformidad de esta ley con el Derecho europeo sino que, por otra, estime igualmente que dicha ley nacional es contraria a la Constitución nacional, y, por ello, haya acudido ya, en un procedimiento paralelo en estado de litispendencia, ante el Tribunal Constitucional (como único competente, en virtud del Derecho nacional, para pronunciarse sobre la inconstitucionalidad de las leyes). La respuesta del TJUE fue positiva ${ }^{119}$.

\section{REFLEXIONES Y PROPUESTAS FINALES: LA EVITACIÓN DE UNA ARGUCIA PROCESAL DOMÉSTICA ANTE EL TJUE}

Llegados a este punto, cabe recapitular sosteniendo que el presente estudio ha pretendido introducir un enfoque novedoso consistente en la evitación, por activa o por pasiva, de una argucia procesal doméstica reveladora de un uso abusivo o desacertado del mecanismo de la cuestión prejudicial ${ }^{120}$. Lo cual equivale a defender la virtualidad de dicho instrumento como vector fundamental del actual constitucionalismo europeo multinivel, tanto más cuanto que a través de él son susceptibles de adquirir plena vigencia los principios basilares del Estado de Derecho y de la UE como comunidad de Derecho.

En consecuencia, se ha sometido a crítica constructiva tanto la estrategia procesal dimanante de un ejercicio espurio de la facultad prevista en el art. 267 TFUE como la inconfesable negativa a ejercer la obligación de planteamiento impuesta por ese mismo precepto. En ambos casos, por acción o por omisión, se pone en jaque la fluida articulación del sistema jurídico europeo (de las normas

119 Este es el fallo del TJUE: «El artículo 267 TFUE debe interpretarse en el sentido de que un órgano jurisdiccional nacional, que albergue dudas acerca de la compatibilidad de una normativa nacional, tanto con el Derecho de la Unión como con la Constitución del Estado miembro de que se trate, no está privado de la facultad ni, en su caso, exento de la obligación de plantear al Tribunal de Justicia de la Unión Europea cuestiones sobre la interpretación o la validez de ese Derecho por el hecho de que esté pendiente un procedimiento incidental de control de la constitucionalidad de esa misma normativa ante el órgano jurisdiccional nacional encargado de ejercer ese control».

120 Una breve crítica reciente con tal filosofía se contiene en la contribución de Prats Albentosa, L.: «Uso y abuso de la cuestión prejudicial ante el TJUE», El Notario del Siglo XXI, n. ${ }^{\circ}$ 69, septiembre/octubre 2016, p. 51: el citado autor subraya el interés general que subyace en la aplicación uniforme del Derecho de la UE como finalidad última de la cuestión prejudicial, apostillando que tan «amplísima» facultad del juez nacional no «es absoluta, ni arbitraria. Pues, en todo caso, el 'diálogo' entre jueces ha de dar lugar a una relación equilibrada, a un 'diálogo cooperativo', en el que el reconocimiento y respeto entre el TJUE y los tribunales nacionales prime sobre criterios de jerarquía», pues «tras tal 'diálogo entre jueces', nacionales entre sí y entre éstos con el TJUE, se encuentra la propia construcción europea, que puede resultar dañada por efecto de un inadecuado entendimiento y aplicación de los principios de competencia y jerarquía de los órganos jurisdiccionales». 
de producción nacional y supranacional) y el correcto reparto del poder judicial europeo (entre la Justicia nacional y supranacional) y, con ello, la óptima realización del sistema europeo de derechos fundamentales.

En estas coordenadas, si la cuestión prejudicial no se perfila como exponente de un sincero diálogo judicial que responda coherentemente, en condiciones de buena fe procesal, al leal cumplimiento de las obligaciones comunitarias (impuesto por mandato constitucional y europeo), se resta credibilidad al conjunto del proceso de integración. Así pues, si la relevancia de la conciencia europea o del sentimiento constitucional europeo constituye una de las claves de ese proceso de integración ${ }^{121}$, el factor humano resulta asimismo determinante en la consecución de un espacio judicial europeo dialogante entre quienes integran los órganos jurisdiccionales y de éstos con los «formantes dinámicos» (es decir, la doctrina) implicados en el diálogo ${ }^{122}$.

En efecto, en los primeros años de integración de España en la Europa comunitaria fue posible comprobar un cierto grado de voluntarismo y entusiasmo en la formulación de las cuestiones prejudiciales, lo cual eventualmente pudo responder a un comprensible déficit de formación en Derecho europeo por parte de la Judicatura y, consiguientemente, ello se plasmó en planteamientos deficitarios que merecieron alguna crítica: así sucedió con respecto a la primera cuestión prejudicial planteada desde España, concretamente mediante Auto de 21 de marzo de 1986, de la Sala Cuarta del Tribunal Central de Trabajo ${ }^{123}$, y que dio lugar a la Sentencia del Tribunal de Luxemburgo de 29 de septiembre de 1987 (Giménez Zaera, asunto 126/86). En paralelo, era lógica asimismo una cierta actitud voluntarista y entusiasta, con disfunciones análogas, en la asunción de los novedosos principios de primacía y efecto directo del Derecho comunitario ${ }^{124}$. No obstante,

121 Esa conciencia y sentimiento europeos pueden y deben ser críticos, no cayendo en un mero «europeísmo ingenuo»: Imbernón, A.: «Spain: Facing a test of maturity», en Keeping Europeans Together. Assessing the State of EU Cohesion (Ed. JANNING, J.), European Council of Foreign Relations, London, 2016, p. 122.

122 Con razón se ha destacado el papel de la crítica doctrinal en la construcción y mejora del sistema jurídico y, como parte de él, del sistema de derechos humanos: así, Pegoraro, L.: «Estudio introductorio: Trasplantes, injertos, diálogos. Jurisprudencia y doctrina frente a los retos del Derecho comparado», en Diálogo Jurisprudencial en Derechos Humanos. Entre Tribunales Constitucionales y Cortes Internacionales (Coords. FERRER MaC-Gregor, E., y Herrera García, A.A.), Valencia, Tirant lo Blanch, 2013, p. 51. En conexión con ello, resulta de gran interés analizar factores como la educación jurídica de los magistrados constitucionales, aspecto que ha sido abordado asimismo con un enfoque comparatista por Pegoraro, L.: «Judges and Professors. The influence of Foreign Scholarship on Constitutional Courts' Decisions», en Courts and Comparative Law (Eds. Andenas, M., y Fairgrieve, D.), Oxford, Oxford University Press, 2015, p. 333.

123 En la doctrina (Ruiz-Jarabo Colomer, D.: El juez nacional como juez comunitario, op. cit., pp. 103104) se ha criticado la extensión del Auto de planteamiento, así como su redacción y lenguaje, el carácter inadecuado de las preguntas o el olvido de decretar la suspensión del trámite del recurso de suplicación.

124 Con carácter general, sobre dicha actitud ha observado Biglino CAmpos, P.: «La primacía del derecho comunitario: una mirada contrapuesta. La perspectiva española», en La Unión Europea en Perspectiva Constitucional (Ed. Carmona Contreras, A.M.), Cizur Menor, Thomson/Aranzadi, 2008, p. 41: «Todavía causa cierto asombro en la doctrina la facilidad con la que los ordenamientos nacionales aceptaron la proclamación del principio de primacía por parte del Tribunal de Justicia. Existen diferentes argumentos que 
los programas de formación deben seguir potenciándose en la actualidad, dada la creciente complejidad del entramado normativo comunitario.

Por tanto, la primera propuesta consiste en continuar mejorando la formación de la Judicatura en Derecho europeo, para evitar estrategias procesales que, voluntaria o involuntariamente, aboquen a planteamientos distorsionadores. Obviamente, de la fase inicial de voluntarismo y de devoción en la utilización del mecanismo de la cuestión prejudicial, hemos evolucionado inexorablemente hacia una fase que debe estar presidida por la voluntad jurisdiccional positiva y por la obligación en el planteamiento prejudicial cuando así se desprenda del art. 267 TFUE.

En este sentido, propongo en segundo lugar que la voluntad jurisdiccional positiva se conciba irremediablemente como buena fe procesal encaminada a formular cuestiones prejudiciales cuyo objeto último sea una armonización al alza en materia de derechos fundamentales. Del mismo modo, cuando el planteamiento obligatorio de la cuestión prejudicial impuesto por el art. 267 TFUE no se verifique, la tercera propuesta pasará por superar los obstáculos de la normativa nacional (por ejemplo, el difícil filtro del amparo constitucional ante esa negativa del órgano jurisdiccional nacional cuyas decisiones no sean susceptibles de recurso) para activar los resortes europeos establecidos al efecto (particularmente, la denuncia de la situación ante la Comisión, para que someta el caso al TJUE mediante el oportuno procedimiento de infracción).

En fin, la última propuesta radica en disciplinar la posible concurrencia de planteamientos prejudiciales en sede jurisdiccional constitucional interna y en sede jurisdiccional comunitaria, en cuyo caso habrá de otorgarse prioridad a la intervención del Tribunal de Luxemburgo con suspensión del procedimiento ante el Tribunal Constitucional (me remito a la propuesta de lege ferenda efectuada en el epígrafe VI.1, supra). Es el mejor antídoto frente a sutiles juegos de doble prejudicialidad que vayan en perjuicio de un resultado armonizador; $y$, si aun así surgieran matices, deberían jugar las cláusulas de estándar mínimo y solución más favorable (principio favor libertatis o pro personae) previstas en las propias normas europeas (entre ellas, las disposiciones de los arts. 52.3 y 53 CDFUE o del art. $53 \mathrm{CEDH}^{125}$ ).

$$
* * *
$$

explican esta conformidad. Para algunos, permitió a los jueces nacionales ponerse en pie de igualdad con otros órganos estatales, ya que les autorizaba a inaplicar las leyes de sus propios Parlamentos sin necesidad de acudir ante sus propias jurisdicciones nacionales. De esta manera, era posible establecer formas de judicial review que no pasan por el Tribunal Constitucional, sino que se fundamentan en la colaboración del juez nacional con el propio TJUE. En estas circunstancias, no tiene nada de extrañar que los recelos hayan provenido, sobre todo de las jurisdicciones constitucionales de los Estados miembros. Son éstas las que, desde un principio, advierten de los problemas de orden interno que suscita para el juez ordinario aplicar el derecho comunitario en detrimento del derecho nacional».

125 Demuro, G.: «I rapporti fra Corte di Giustizia delle Comunità Europee e Corte Europea dei Diritti dell'Uomo», en La Corte Costituzionale e le Corti d'Europa (Coord. Falzea, P., Spadaro, A., y Ventura, L.), Torino, Giappichelli, 2003, p. 58. 
TITLE: European Preliminary Rulings versus more than doubtful Approaches

ABSTRACT: This article takes as its starting point the importance of the preliminary ruling as a fundamental instrument of the current multi-level European constitutionalism, since it allows for strengthening the basic principles of the rule of law at both the State level and the EU level (especially legal certainty, responsibility, due process of law and optimization of fundamental rights). With such a premise, a critical analysis of more than dubious strategies (not always apparently guided by good procedural faith) is carried out. Indeed, these strategies, by action or omission, breach Article 267 TFEU by challenging the fluid articulation of the European legal system (of national and supranational provisions) as well as the correct distribution of the European judicial power (between national and supranational courts) and, as a result, the optimal realization of the European system of fundamental rights. Finally, the paper concludes with proposals that seek to improve supranational judicial dialogue through a true spirit of collaboration supported by a solid training of judges in European law, a positive jurisdictional will (inspired by the favor libertatis principle), a re-dimension of the obligation to submit the preliminary ruling in the cases referred to in Article 267 TFEU and a specific discipline of a double preliminary ruling (both before the national Constitutional Court and before the Court of Justice).

RESUMEN: El presente artículo toma como punto de partida la importancia de la cuestión prejudicial como instrumento fundamental del actual constitucionalismo europeo multinivel, en la medida en que a través de él cabe dotar de fuerza a los principios esenciales del Estado de Derecho y de la UE como comunidad de Derecho (especialmente seguridad jurídica, responsabilidad, tutela judicial efectiva y optimización de los derechos fundamentales). Con tal premisa, se efectúa un análisis crítico de estrategias más que dudosas (no siempre aparentemente guiadas por buena fe procesal) que, por acción o por omisión, vulneran el artículo 267 TFUE poniendo en entredicho la fluida articulación del sistema jurídico europeo (de las normas de producción nacional y supranacional) y el correcto reparto del poder judicial europeo (entre la Justicia nacional y supranacional) y, con ello, la óptima realización del sistema europeo de derechos fundamentales. Finalmente, el trabajo concluye con unas propuestas que pretenden mejorar el diálogo judicial supranacional a través de un verdadero espíritu de colaboración que tenga el respaldo de una sólida formación de la Judicatura en Derecho europeo, de una voluntad jurisdiccional positiva (inspirada en el principio favor libertatis), de una dinamización de la obligación de formulación la cuestión prejudicial en los casos previstos en el artículo 267 TFUE y de una disciplina precisa de la doble prejudicialidad (ante la Jurisdicción Constitucional nacional y ante el Tribunal de Justicia).

KEY WORDS: Multi-level European constitutionalism, judicial collaboration, loyal cooperation, procedural strategy, good faith, responsibility, double preliminary ruling, favor libertatis.

Palabras Clave: Constitucionalismo europeo multinivel, colaboración judicial, cooperación leal, estrategia procesal, buena fe, responsabilidad, doble prejuidicialidad, favor libertatis.

FECHA DE RECEPCIÓN: 18.12.2016 FECHA DE ACEPTACIÓN: 01.02.2017 